Georgia State University

ScholarWorks @ Georgia State University

$12-16-2015$

\title{
Exploring the Differential Associations between Components of Executive Functioning and Reactive and Proactive Aggression
}

Lisa Hecht

Follow this and additional works at: https://scholarworks.gsu.edu/psych_theses

\section{Recommended Citation}

Hecht, Lisa, "Exploring the Differential Associations between Components of Executive Functioning and Reactive and Proactive Aggression." Thesis, Georgia State University, 2015.

doi: https://doi.org/10.57709/7909724

This Thesis is brought to you for free and open access by the Department of Psychology at ScholarWorks @ Georgia State University. It has been accepted for inclusion in Psychology Theses by an authorized administrator of ScholarWorks@ Georgia State University. For more information, please contact scholarworks@gsu.edu. 


\title{
EXPLORING THE DIFFERENTIAL ASSOCIATIONS BETWEEN COMPONENTS OF EXECUTIVE FUNCTIONING AND REACTIVE AND PROACTIVE AGGRESSION
}

by

\author{
LISA HECHT \\ Under the Direction Of Robert D. Latzman (Ph.D.)
}

\begin{abstract}
The current study explored the nuanced associations between components of executive functioning (EF) and subtypes of aggression, using a latent variable approach. Participants were racially diverse undergraduate students who completed a self-report of reactive (RA) and proactive aggression (PA), and traditional neuropsychological tasks of EF. The appropriateness of using a nested bifactor model of EF was confirmed, and this bifactor model of EF was used to examine the specific associations between components of EF and RA and PA. Results revealed components of EF are differentially associated with RA and PA, such that impulsive, provoked aggression is associated with lower levels of goal-oriented inhibition and higher levels of flexibility, whereas planned, goal-oriented aggression is associated with higher levels of working memory. Findings from the current study underscore the importance of considering the multidimensional nature of $\mathrm{EF}$ as well as aggression when examining their associations with external constructs of interest.
\end{abstract}

INDEX WORDS: Executive functioning, aggression, reactive aggression, proactive aggression 
EXPLORING THE DIFFERENTIAL ASSOCIATIONS BETWEEN COMPONENTS OF EXECUTIVE

FUNCTIONING AND REACTIVE AND PROACTIVE AGGRESSION

by

LISA HECHT

A Thesis Submitted in Partial Fulfillment of the Requirements for the Degree of Master of Arts

In the College of Arts and Sciences

Georgia State University

2015 
Copyright by Lisa Hecht 2015 
EXPLORING THE DIFFERENTIAL ASSOCIATIONS BETWEEN COMPONENTS OF EXECUTIVE FUNCTIONING AND REACTIVE AND PROACTIVE AGGRESSION

by

\section{LISA HECHT}

Committee Chair: Robert Latzman

Committee: Dominic Parrott

David Washburn

Scott Lilienfeld

Electronic Version Approved:

Office of Graduate Studies

College of Arts and Sciences

Georgia State University

December 2015 


\section{DEDICATION}

This thesis is dedicated to my mother, Cristine Sutter, who gave me the space to learn; my father, Jeff Hecht, who taught me to relentlessly pursue my passions and question everything; and my grandfather, Robert Sutter, who showed me the importance of unwavering patience and positivity. 


\section{ACKNOWLEDGEMENTS}

First I would like to acknowledge my graduate advisor, Dr. Robert Latzman, for his continued guidance and support with this project as well as the rest of my graduate training. I am grateful for his invaluable perspective, his encouragement, and his patience. I also thank Dr. Scott Lilienfeld for his support with this project as well as many others. I very much appreciate his thoughtful feedback, insight, and encouragement. I also thank Dr. David Washburn for his thoughtful comments and questions, and Dr. Dominic Parrott for his valuable perspective and suggestions. As a whole, my thesis committee pushed me to think broadly and critically, for which I am extremely grateful. I would also like to thank Dr. Amy Lansing, who provided me with invaluable mentorship and experience early in my academic career, and who engendered and supported my wide range of interests. Additionally, I would like to thank my sister, Dr. Erin Hecht, for setting a high bar and providing the support and guidance to pursue it. Finally, I would like to thank my family, Cristine Sutter, Jeff Hecht, and Linda Lewis for their love and encouragement, and Ruschelle Leone for her friendship and camaraderie. 


\section{TABLE OF CONTENTS}

ACKNOWLEDGEMENTS ................................................................................... v

LIST OF TABLES .................................................................................................... viii

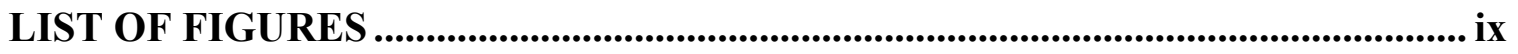

1 INTRODUCTION.............................................................................................. 1

1.1 Reactive and Proactive Aggression...................................................................... 2

1.2 Executive Functioning and Aggression ......................................................... 4

1.3 Self Regulatory Abilities and Reactive \& Proactive Aggression...................... 7

1.4 EF as a Multidimensional Construct ......................................................9

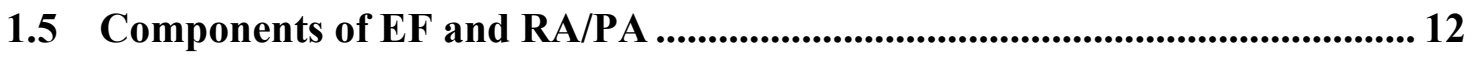

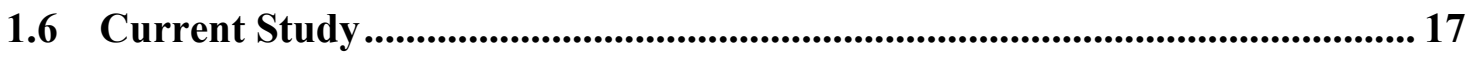

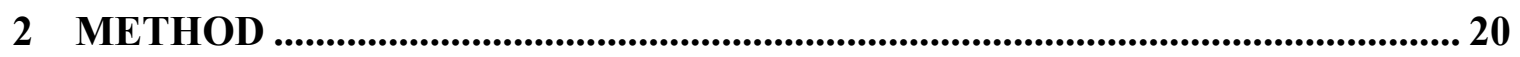

2.1 Participants ............................................................................................................. 20

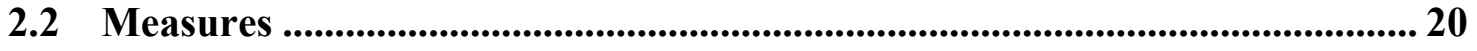

2.3 Analyses....................................................................................................... 22

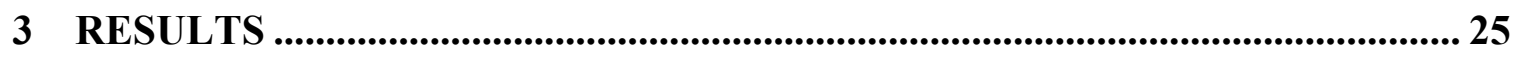

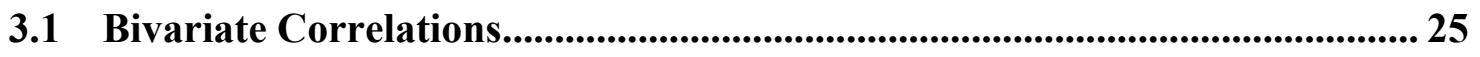

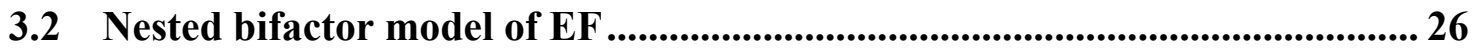

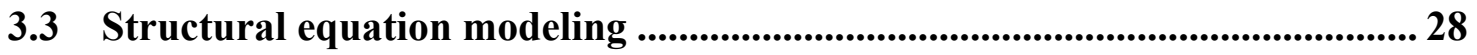

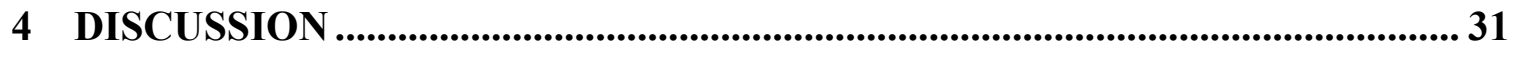


4.1 Nested, bi-factor model of EF......................................................................... 32

4.2 Associations between components of EF and RA/PA ............................... 35

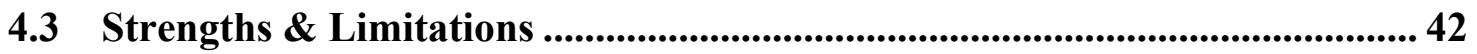

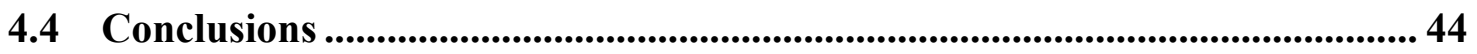

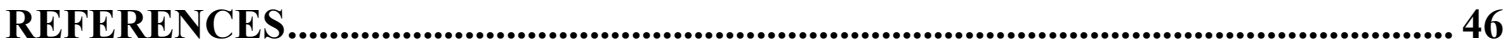




\section{LIST OF TABLES}

Table 1. Bivariate correlations among covariates, D-KEFS scaled scores, and raw and residual

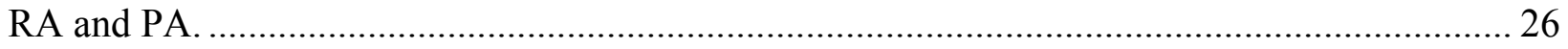

Table 2. Fit Indices for the bifactor and structural models. ................................................. 27 


\section{LIST OF FIGURES}

Figure 1. Measurement model depicting nested, bifactor model of EF................................... 28

Figure 2. Structural model depicting latent components of EF and their association with latent

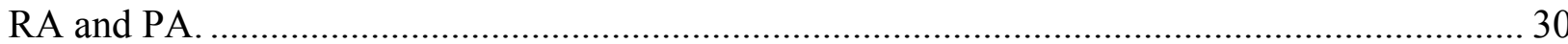




\section{INTRODUCTION}

Individuals who engage in antisocial and aggressive behaviors constitute a broad and heterogeneous group, with multiple processes contributing to the onset and persistence of these behaviors (e.g., Broidy et al., 2003; Loeber \& Hay, 1997; Herrenkohl et al., 2000; Moffitt, 1993, Tremblay, 2000). Consequently, in an attempt to delineate this heterogeneous construct, researchers have aimed to identify and define subtypes of aggression in service of better understanding and distinguishing between pathways to aggression. One commonly made distinction in the literature is that between reactive (RA) and proactive (PA) aggression. These subtypes of aggression are primarily differentiated based upon the function of, or motivation underlying the act: whereas RA is an impulsive, emotionally-laden response to a provocation, PA is a planned act committed as a means to achieve a secondary goal (Berkowitz, 1993; Dodge, 1991; Raine et al., 2006).

A large body of literature confirms the importance of cognitive functioning, and particularly executive functioning (EF), in the explanation of aggressive and antisocial behaviors (e.g., Giancola, 1995; Morgan \& Lilienfeld, 2000; Ogilvie et al., 2011; Seguin, 2009; Seguin \& Zelazo, 2005). EF consists of higher order cognitive abilities involved in goal attainment via problem solving processes, such as working memory, planning, representation of mental sets, and self-control (e.g., Seguin \& Zelazo, 2005). Factor analytic research frequently reveals that EF is comprised of separable yet related components, including inhibition, conceptual flexibility, and monitoring (e.g., Latzman \& Markon, 2010; Miyake et al., 2000; Miyake \& Friedman, 2012). Despite the importance of EF in the explanation of aggression broadly, there is a relative dearth of research investigating the associations between specific components of EF and these subtypes of aggression. This 
paucity of research is surprising, given that a critical distinction between RA and PA is the level of planning and impulsivity behind the behavior. This important theoretical distinction indicates that RA and PA may involve different cognitive processes. Moreover, in light of a growing body of literature indicating RA and PA are differentially associated with constructs related to EF, it appears especially important to consider components of EF in relation to these subtypes of aggression. As such, in the current study I aim to investigate the common and distinct associations between basic executive functioning processes and RA and PA.

\subsection{Reactive and Proactive Aggression}

Contemporary definitions of aggression focus on the goal underlying the behavior: specifically, aggressive behaviors are acts committed against another person with the intent to cause harm, such that the target is motivated to avoid the behavior (e.g., Anderson \& Bushman, 2002; Baron \& Richardson, 1994; Berkowitz, 1993; Parrott \& Giancola, 2007). Clearly, this broad construct of general aggression encompasses a wide variety of behaviors that arise for a multitude of reasons, and can be expressed through various routes, including verbal, relational, and physical (Crick \& Grotpeter, 1995). Given this heterogeneity, researchers frequently parse aggression into meaningful and specific subtypes. One commonly made distinction is based on the function, or primary purpose of the behavior: reactive aggression (sometimes referred to as impulsive or affective aggression), and proactive aggression (sometimes referred to as instrumental or planned aggression).

The concept of RA traces its roots back to the frustration-aggression model (e.g., Berkowitz, 1993) and is an impulsive, angry, and defensive response to a provocation. In 
contrast, the concept of PA has its roots in social learning theory (e.g., Bandura, 1978) and is a premeditated, planned, and deliberate act that is committed as a means to achieve a secondary goal. Research indicates RA and PA are related, but separable constructs (e.g., Raine et al., 1996; Poulin \& Boivin, 2000). Indeed, RA and PA tend to be highly correlated (Poulin \& Bouvin, 2000), and as such, some have argued the distinction between RA and PA lacks utility (e.g., Bushman \& Anderson, 2001). Nevertheless, RA and PA exhibit differential correlates (e.g., Brendgen et al., 2001; Conner et al., 2004; Hecht, Berg, Lilienfeld, \& Latzman, in press; Latzman et al., 2011; Latzman \& Vaidya, 2013), and relate to different outcomes (Fite et al., 2010). Moreover, when overlapping variance between RA and PA is statistically accounted for through the use of residual aggression scores, their associations with external correlates appear to become even more distinct (e.g., Cima \& Raine, 2009; Hecht \& Latzman, 2015; Hecht et al., in press). Such differences support the distinction between RA and PA, and are indicative of potentially different etiological pathways underlying these subtypes of aggression (Crick \& Dodge, 1996; Latzman et al., 2011; Raine et al., 2006). Although the integration of social-cognitive factors (e.g., social-information processing theory; Crick \& Dodge, 1994) into the study of aggression has contributed to our understanding of differential processes underlying RA and PA, relatively few studies have explicitly examined the contribution of more basic neurocognitive mechanisms associated with these subtypes of aggression. As noted above, one understudied but promising potential differential contributor to RA and PA is the constellation of higherorder cognitive abilities involved in self-regulation and goal attainment, known as executive functions. 


\subsection{Executive Functioning and Aggression}

EF is a broad construct that is often recognized as important for self-regulation (Gyurak et al., 2009; Patrick, Blair, \& Maggs, 2008) in the service of organized, goaloriented behavior (Friedman et al., 2008; McCabe et al., 2010; Miyake et al., 2000). Researchers approach the study of these self-regulatory abilities from different frameworks. Whereas some take an EF perspective, others frequently approach selfregulatory abilities from a temperament framework, through the construct of effortful control, or disinhibition (e.g., Latzman \& Vaidya, 2013; Rothbart, Derrberry, \& Posner, 1994; Rothbart, Ellis, Rueda, \& Posner, 2003; Rueda, Posner, \& Rothbart, 2005). Although some have argued that EF and effortful control are distinct constructs (Blair and Ursache, 2011), recent research demonstrates significant overlap between the two (e.g., Bridget et al., 2013; Rueda, Posner, \& Rothbart, 2011). Nevertheless, exactly which aspects of EF overlap with effortful control is unclear. Whereas some researchers suggest effortful control is most strongly associated with aspects of EF related to inhibition (e.g., Carlson \& Moses, 2001; Ellis, Rothbart, \& Posner, 2004; Nigg, 2000), others argue it is the updating or monitoring EF abilities that are most relevant (e.g., Bridgett et al., 2013). Although the degree of overlap between specific aspects of EF and effortful control is variable, it may be most prudent to consider these constructs as two related, yet distinct levels of analysis from which to study disinhibitory psychopathology (e.g., Nigg, 2000).

Self-regulatory abilities have been implicated as both risk (e.g., Nigg, 2000; Eisenberg, Spinrad, \& Eggum, 2010) and protective factors (e.g., Eisenberg et al., 1997) in relation to various outcomes, including aggression. Not unexpectedly, EF has been found to affect social competence (e.g., Razza \& Blair, 2009), and deficits in EF have been associated 
with risky and maladaptive outcomes such as antisocial behavior and aggression (Macdonald, 2008). Presumably, deficits in EF may lead to a decrease in behavioral inhibition, which in turn, results in increased levels of aggression (e.g., Giancola, 1995; Seguin, 2009). Seguin \& Zelazo (2005) posit that EF plays a central role in aggression, and observe that the development of EF during childhood and adolescence corresponds with a decline in physical aggression. They suggest that self-regulatory abilities involved in EF are essential for social competence and inhibiting aggressive behavior (Seguin \& Zelazo, 2005). Indeed, deficits in EF may result in poor strategy formulation, cognitive inflexibility, or impulsiveness, leading to a propensity for disinhibited aggressive behavior (Dolan \& Anderson, 2002; Pihl et al., 2003). Meta-analytic studies confirm this relationship, as strong associations have consistently been found between deficits in EF and the engagement in aggressive and antisocial behaviors, across various methodological approaches (e.g., Morgan \& Lilienfeld, 2000; Ogilvie et al., 2011).

EF is widely believed to be largely, although not exclusively, mediated by the frontal cortex (e.g., Miller \& Cohen, 2001; Posner \& Rothbart, 2000). Moreover, neuropsychological (Best, Williams, \& Coccaro, 2002; Lapierre et al., 1995; Seguin et al., 1995; Yeudall \& fromm-Auc, 1979), lesion (e.g., Damasio et al., 1994; Grafman et al., 1996; Tranel, 1994), and neuroimaging studies (e.g., Raine et al., 1998) all implicate the frontal cortex in aggression (see Brower \& Price, 2001, for a review). A number of regions in the frontal cortex have been shown to be important for the control of angry and aggressive urges, including the orbitofrontal cortex, anterior cingulate cortex, medial prefrontal cortex, and dorsolateral PFC (Davidson, Putnam, \& Larson, 2000; Denson, 2011; Macdonald, 2008; Siever, 2008). These regions have also been shown generally to support self-control, 
including self-regulation of emotion (Heatherton, 2011; Ochsner \& Gross, 2008). Overall, this literature confirms that EF and aggression share an overlapping neurobiological basis, further highlighting the role of EF in aggressive behaviors.

Although a large literature associates aggression with deficits in frontal lobe functioning and EF, a smaller body of literature suggests some antisocial and aggressive behaviors are associated with higher performance on tasks of EF. For example, Barker and colleagues (2007) examined the developmental trajectories of physical violence and theft in adolescents using a longitudinal design. Whereas frequent physical violence was associated with deficits in EF and verbal abilities, frequent theft was associated with increased levels of both EF and verbal abilities. It is possible that antisocial acts involving increased levels of planning and premeditation may be associated with higher levels of $\mathrm{EF}$ (Barker et al., 2007). Indeed, neuroimaging research indicates that criminals who committed planned and deliberate murders exhibited prefrontal cortex functioning similar to that of non-criminal comparison subjects, whereas those who committed impulsive, affectively-motivated murders exhibited marked abnormalities in prefrontal cortex functioning (Raine et al., 1998). As such, it appears that some antisocial and aggressive acts may require higher levels of certain aspects of EF, such as planning and conceptual flexibility, whereas others are associated with lower levels of EF.

Overall, the above-reviewed literature indicates that aggression is associated with deficits in EF. Yet, given that a small body of literature indicates certain antisocial behaviors are associated with increased levels of $\mathrm{EF}$, a more nuanced picture may emerge when considering EF's association with specific types of aggression. Indeed, aggregating heterogeneous antisocial behaviors into a single grouping (such as broad aggression) can 
mask important developmental differences, and may impede the identification of mechanisms underlying such behaviors (Barker et al., 2007). As such, investigations of EF's association with aggression generally lack specificity, and may overlook important differential relationships between EF and specific subtypes of aggression.

\subsection{Self Regulatory Abilities and Reactive \& Proactive Aggression}

Important differences have been found between RA and PA with relation to cognitive and self-regulatory abilities. The social-cognitive literature suggests that impulsive, provoked aggression arises as a result of an impairment in social-information processing, such as poor cue encoding and interpretation of cues, which then leads to hostile attributional bias (Crick \& Dodge, 1996; Ellis et al., 2009; Walters, 2007) and deficits in social problem solving (Dodge et al. 1997). In addition, a number of studies point to selfregulatory problems as important correlates of RA. For instance, several studies have linked RA to impairments in executive functioning (e.g., Ellis et al., 2009; Giancola et al., 1996; Stanford, Greve, \& Gerstle, 1997), and particularly verbally-mediated executive functions (Greve et al., 2002; Villemarette-Pittman et al., 2003). Children engaging in RA also tend to be rated as more inattentive (Dodge et al., 1997; Vitaro, Brendgen, \& Tremblay, 2002) and impulsive (Dodge et al., 1997) than proactively- or non-aggressive children. RA has also been associated with lower trait self-control (Latzman et al., 2011; Latzman \& Vaidya 2013), higher levels of impulsivity (Miller \& Lynam, 2006) and particularly impulsivity during periods of negative affect (Hecht \& Latzman, 2015), increased substance abuse (Hubbard et al., 2002), and increased hyperactivity (McAuliffe et al., 2006). In terms of outcomes, compared to proactively aggressive children, reactively aggressive children experience poorer psychosocial adjustment (e.g., Card \& Little, 2006) and are less likely to 
be accepted and more likely to be victimized by their peers (Dodge et al., 1990; Dodge et al., 1997; Vitaro et al., 2006).

In contrast, PA is associated with positive outcome expectations (Walters, 2007) as well as valuing aggression as a means to achieve desired goals (Dodge et al., 1997). Few studies have considered the role of specific cognitive processes in PA; however, it appears that PA may not be associated with the same executive functioning impairments as RA (Ellis et al., 2009). Further, PA is less strongly associated with (Latzman \& Vaidya, 2013) or not associated with (Latzman et al., 2011) lower levels of self-control, although this finding is not unequivocal, as impulsivity-related psychopathic personality traits have been found to be more strongly associated with PA than RA (Hecht et al., in press). Proactivelyaggressive children also do not display the same difficulties with attention exhibited by those who engage in RA or a combination of RA and PA, and informants rate PA children lower on impulsivity than RA children (Dodge et al., 1997). RA and PA are also associated with differential outcomes. For example, longitudinal research indicates adolescent RA is associated with negative emotionality and anxiety in adulthood, while proactive aggression is associated with psychopathic personality traits and antisocial behavior in adulthood (Fite et al., 2010).

All told, the extant literature indicates RA and PA may result from different underlying cognitive processes, and highlights the importance of self-regulatory abilities, such as EF, in the explanation of RA and PA. Overall, RA is characterized by cognitive impairments, and particularly processes related to EF, such as low self-control and problems with inhibition. Although not unequivocal, PA is characterized by relatively higher levels of these processes, such as increased self-control and an ability to plan and 
carry out goal-directed acts of aggression. Moreover, given that the theoretical distinction between RA and PA rests primarily upon the level of impulsivity and planning underlying the act, and given the importance of EF in the explanation of general aggression, it appears especially important to investigate the potential differential associations between EF and both RA and PA. Nevertheless, very few studies have examined EF specifically in relation to RA and PA, and an even smaller number of studies consider EF as a multidimensional construct. However, EF is a heterogeneous construct that can be parsed into meaningful components such as inhibition, switching between mental sets, and updating information in service of goal attainment (Miyake et al., 2000). To further clarify the role of selfregulatory abilities in the differentiation of RA and PA, and to understand EF's contribution more specifically, it is important to consider the construct of EF at the component level.

\subsection{EF as a Multidimensional Construct}

As noted previously, EF represents a constellation of higher-order cognitive processing abilities important for problem solving in the service of goal attainment. Nevertheless, EF is a complex construct that is difficult to define (Jurado \& Rosselli, 2007) and to measure (Miyake \& Friedman, 2012). One reason for this is what is known as the "task impurity" problem. Tasks designed to measure EF necessarily involve the use of multiple cognitive processes, including non-EF processes such as perception, attention, and memory. As such, scores from EF tasks are confounded by variance attributable to other non-EF processes, making it difficult to isolate that which is attributable to the specific EF of interest (e.g., Miyake et al., 2000; Miyake \& Friedman, 2012; Washburn, Latzman, Schultz, \& Bramlett, 2015). Recent efforts by Miyake and colleagues (2000; 2012) as well as others (e.g., Latzman \& Markon, 2010; Lehto et al., 2003) have resulted in significant 
advances regarding the task impurity problem common among EF measures. Using factor analytic approaches, these investigations have resulted in the identification of isolated components of EF. This approach allows for multiple EF tasks to be used as indicators of a single target EF component, such that common processes across tasks are statistically extracted into a single, more pure estimate of the target EF (Miyake \& Friedman, 2012).

Overall, these factor analytic studies have revealed that EF involves separable but related components, although the exact structure of these components varies in the literature. In the original framework, Miyake \& colleagues (Miyake et al., 2000; Miyake \& Friedman, 2012) have demonstrated considerable empirical support for a 3-factor model of EF, which has been further supported by results from numerous studies that reveal the same pattern across various samples and using various EF tasks (Friedman et al., 2011; Latzman \& Markon, 2010; Rose, Feldman, \& Jankowski, 2011; Vaughan \& Giovanello, 2010). The three separable, yet related components of EF have been termed Inhibition (Latzman \& Markon, 2010; Lehto et al., 2003; Miyake et al., 2000), Monitoring (Latzman \& Markon, 2010; also referred to as "Working Memory" by Lehto et al., 2003, and "Updating" by Miyake et al., 2000), and Conceptual Flexibility (Latzman \& Markon, 2010; also termed "Shifting" by Lehto et al., 2003 and Miyake et al., 2000). The Inhibition component reflects an individual's ability to control or inhibit dominant or automatic responses to stimuli; Monitoring involves the tracking and appraisal of incoming task information as well as the updating of information in working memory if appropriate; and Conceptual Flexibility involves shifting between tasks and performing new tasks while dealing with proactive interference from the previous task. 
Recently, this original three-factor model has been reconsidered, as emerging research indicates that a nested model may better capture the separable but related structure among factors of EF (e.g., Friedman et al., 2008; 2011). Laying the groundwork for a nested model, Friedman and colleagues (2008) conducted a hierarchical latent variable model in which all three latent components of $\mathrm{EF}$ were specified to indicate a latent, higher-order "Common EF" factor. Because the Inhibition component was found to correlate perfectly (i.e., $r=1.0$ ) with the Common-EF factor, Friedman and colleagues demonstrated that individual differences in inhibitory abilities are entirely explained by the variance that is common across all EF tasks. Thus, the unity and diversity of EF appears to be better captured through a nested, bifactor model, than through the original threefactor framework (Miyake \& Friedman, 2012). In this model, the unity of EF is represented by a "Common EF" factor, which encompasses the shared variance across all EF tasks. Once this common variance is accounted for, there is no longer enough inhibition-specific variance to manifest its own factor. In comparison, the diversity of EF is represented by "Updating-specific" and "Shifting-specific" factors, each of which encompass the variance unique to their respective components of EF. Although no studies to date have leveraged more traditional neuropsychology-based tasks of EF to model EF using this nested, bifactor approach, the framework has received considerable support across various independent samples using computerized EF tasks (for a review, see Miyake \& Friedman, 2012), and is increasingly utilized to disentangle EF's association with external correlates (e.g., personality; Fleming, Heintzelman, \& Bartholow, 2015).

The unity and diversity of EF also appears to be biologically based. Specifically, although researchers have yet to reach a consensus as to the precise localization of EF 
components within the brain, research does suggest that specific EF components may be differentially associated with specific regions within the frontal cortex, and particularly the prefrontal cortex (e.g., Robinson et al., 2013). Moreover, research using a latent variable framework of EF has also revealed that individual differences in the unity (Common EF) and diversity (Updating-specific and Shifting-specific EF) aspects of EF have a substantial genetic contribution (Friedman et al., 2008), indicating that EF appears to have a complex genetic structure (Miyake \& Friedman, 2012). Taken together, in light of the strong empirical support for the unity and diversity of EF across multiple levels of analysis (genetic, neuroanatomical, and task-based), it appears crucial to account for the unity and diversity of EF when considering EF's associations with external correlates, such as aggression.

\subsection{Components of EF and RA/PA}

Indeed, a small but growing body of literature focuses on various of aspects of EF in relation general aggression, rather than considering EF as a single unitary construct. For example, youth engaging in higher levels of aggressive behavior exhibit impairments in tasks involving inhibition, conceptual flexibility, and monitoring abilities compared to controls (Hughes et al., 1998; Raaijmakers et al., 2008), with the greatest differences observed on tasks tapping inhibition. However, surprisingly few studies have explicitly examined the specific associations with subtypes of aggression, such as RA and PA. Nevertheless, it is important to consider common as well as potentially distinct associations between components of EF and these subtypes of aggression. Such investigations have the potential to contribute to an understanding of the neurobiological processes underlying different behavioral manifestations of aggression, which can 
ultimately assist in laying the groundwork for the development of preventative interventions (Beauchaine et al., 2008).

The few studies that do explicitly examine the specific associations between EF and RA and/or PA are limited by methodological issues that obscure findings: specifically, failing to simultaneously consider RA and PA; or failing to represent the unity and diversity of EF adequately in measurement and/or analysis. For example, Stanford, Greve, \& Gerstle (1997) examined EF and self-reported impulsiveness in a small sample of college students $(\mathrm{N}=24)$ who were classified as "impulsive aggressive" and "non-aggressive" based on their self-report of aggressive episodes in the past six months. Although this study utilized several measures tapping various EF abilities, all of the significant group differences were based on performance on the Wisconsin Card Sorting Test (WCST). The impulsiveaggressive individuals exhibited impairments in responding appropriately to competing task demands, impulse control, and verbal strategic processing, as well as increased perseverative errors, while their non-aggressive peers did not. Building on Stanford, Greve, and Gerstle (1997), Villemarette-Pittman and colleagues (2003) employed the same criteria for classifying impulsive- and non-aggressive college students, and examined both language and executive functioning by utilizing five language measures with increasing levels of executive demands. Individuals who reported engaging in impulsive aggressive outbursts also exhibited problems organizing verbal information, which the authors theorized may be an indication of executive dysfunction rather than a verbal weakness specifically (Villemarette-Pittman et al., 2003).

Whereas the studies by Villemarette-Pittman and colleagues (2003) and Stanford, Greve, and Gerstle (1997) both classified individuals as impulsive- or non-aggressive to 
examine group differences in EF, Giancola et al. (1996) used a prospective design to examine EF's prediction of self-reported RA among a sample of 291 boys at a two-year follow up assessment. The authors utilized five neuropsychological tasks tapping various components of EF (planning, attention, abstract reasoning, foresight, judgment, selfmonitoring, and motor control) to model a single, latent EF factor, and associated it with RA. The authors found a deficit in the latent $\mathrm{EF}$ factor to be predictive of RA in youth who had a family history of substance abuse, but not for those without such history.

Overall, these studies indicate RA is associated with lower levels of EF; however, by comparing impulsive aggressive or individuals engaging in RA to non-aggressive individuals, the way in which EF may relate to both impulsive as well as planned acts of aggression remains unanswered. Moreover, from this literature it is unclear precisely which components of EF are most relevant to RA. One reason for this is that single scores from complex or broad neuropsychological measures involving multiple EF processes, such as those from the WCST, are susceptible to the task impurity problem described previously (e.g., Miyake et al., 2000). As indicated above, the significant group differences in Stanford, Greve, and Gerstle's (1997) study were on various scores from the WCST. Although this task is a frequently used measure of $\mathrm{EF}$, it is a complex task and performance deficits can arise for a variety of reasons. As such, the way in which EF processes are involved in performance on such tasks is unclear (Miyake et al., 2000). Further, although commonly thought to be a set-shifting task, performance on the WCST has been shown to involve multiple component processes of EF, including shifting and inhibition (Miyake et al., 2000). As such, it is unclear from Stanford, Greve, \& Gerstle's (1997) study precisely which EF processes might be implicated in RA. Similarly, by combining multiple tasks tapping 
various EF component processes into a single factor of EF, Giancola et al. (1996) may have unintentionally masked important differential associations between components of EF and RA/PA. Overall, a major limitation of the above-reviewed studies is that although they utilized impulsive aggression (conceptually similar to RA) or RA, they did not simultaneously examine the potential differential role of EF in RA and PA at the component level.

To date, one study has examined both RA and PA in relation to components EF; however, the operationalization of EF, RA, and PA renders findings difficult to interpret. In a sample of 84 boys in elementary school, Ellis et al. (2009) examined how specific deficits in EF relate to RA and PA as assessed via a six-item teacher-report (Dodge \& Coie, 1987). The authors utilized performance on three tasks as indicators of EF: perseverative errors on the WCST was used as an indicator of cognitive flexibility; total number of moves on the Tower of Hanoi (TOH) was used as an indicator of planning ability; and number of selfcorrections on the Stroop Color-Word Interference Task was used as an indicator of response inhibition. At the bivariate level, Ellis et al. (2009) found RA to be significantly positively associated with response inhibition deficits and problems with planning, whereas PA was not significantly associated with any of the EF variables. The authors then conducted three regression analyses for RA and PA. In each model, RA or PA was used to predict each individual component of EF. The authors also considered the potential moderating role of two social information processing variables: hostile attributional bias and hostile cue encoding. RA was positively associated with response inhibition difficulties, but not significantly associated with planning or conceptual flexibility; however, significant interactions were found, such that individuals with higher levels of social information 
processing deficits exhibited stronger associations between response inhibition and RA, as well as planning and RA. Whereas no main effects were found between PA and any of the EF variables, a significant interaction emerged such that individuals with higher levels of social information processing deficits exhibited a stronger negative association between planning deficits and PA. Taken together, these findings indicate that EF deficits, and particularly inhibition, may be associated with RA, but that PA appears to be unrelated or possibly negatively related to specific deficiencies in EF (Ellis et al., 2009).

Several methodological issues cause Ellis et al.'s (2009) findings to be difficult to interpret. Specifically, the authors utilized the WCST and TOH as indicators of EF, yet it is unclear which component processes of EF are involved in these tasks. Both are complex neuropsychological tasks tapping involving many cognitive abilities, and are thus susceptible to the task impurity problem as performance likely involves multiple components of EF as well as nonexecutive cognitive processes (Miyake et al., 2000). Further, although Ellis et al. (2009) conceptualized TOH performance as tapping planning abilities, as noted previously, factor analytic studies have found performance on a similar tower task to load inconsistently on various components of EF (Latzman \& Markon, 2010), and performance on $\mathrm{TOH}$ to load uniquely on the inhibition component (Miyake et al., 2000). As such, it is possible that Ellis et al.'s (2009) "planning" component was actually an indicator of aspects of EF more related to inhibition, which may better represented in a nested bifactor framework as a component of EF that is important for performance across all EF tasks (Friedman et al., 2008; 2011; Miyake \& Friedman, 2012). All told, the complexity of these tasks, as well as their lack of adequate construct validity, obscures conclusions regarding what the tasks actually measure. Further, by running separate 
hierarchical regression models for each component of EF, Ellis et al. (2009) did not account for shared variance among components of EF. As reviewed above, components of EF are related yet separable (as are RA and PA); therefore, accounting for the unity and diversity of EF is vital to understanding the unique relationships between EF and RA/PA.

It is also important to consider various approaches to the operationalization of RA and PA, as some measurement approaches may have advantages over others. For example, Ellis et al. (2009) utilized a teacher-report operationalization of RA and PA. Yet, motivation is often intrinsic and not observable by outsiders, and it may not be fully unveiled via teacher-report. Considering the centrality of motivation in the distinction between RA and PA, it may be prudent to explore other avenues for the assessment of RA and PA, particularly those that might better differentiate between RA and PA by elucidating the private motivations behind the aggressive acts. Specifically, self-report measures of RA and PA may be more useful than objective teacher ratings when it comes to identifying private motivations behind aggressive acts (Raine et al., 2006).

\subsection{Current Study}

In the current study, the specific associations between components of EF (i.e., its unity and diversity) and subtypes of aggression (i.e., RA and PA) are explored. Given that RA and PA potentially represent different etiological pathways to aggression (e.g., Crick and Dodge, 1996), and are longitudinally associated with different outcomes (e.g., Fite et al., 2010), investigations of the common and distinct associations between components of EF and RA/PA may provide more insight into the development of aggression. Such investigations will lay the groundwork for identifying pathways from EF to various subtypes of aggression, and potential avenues through which to intervene. 
The current study improves upon the above-reviewed literature by utilizing a reliable and valid self-report measure of RA and PA, allowing the respondent to indicate his or her individual motivations behind aggression. RA and PA are highly correlated, which has obscured conclusions regarding their associations with external constructs such as aggression. Thus, in the current study, both RA and PA's shared as well as unique variance is considered in analyses. Consistent with previous research (i.e., Cima \& Raine, 2009; Hecht \& Latzman, 2015; Hecht et al., in press), in bivariate analyses, in addition to raw scores, residual RA/PA scores are used to index "pure" RA and PA independent of each other. Similarly, through the use of structural equation modeling, overlapping variance between RA/PA is taken into account.

In addition to this more nuanced investigation of RA and PA, the current study further improves upon the previous literature though the use of a nested, bifactor model of EF using traditional neuropsychology-based indicators of EF. As described previously, this approach is consistent with a growing body of literature revealing that EF is comprised of separable but related components, not adequately captured through aggregate EF scores, which are best conceptualized through the unity (Common EF) and diversity (Monitoringand Conceptual Flexibility specific-EF) framework (Miyake \& Friedman, 2012). Further, by including all variables simultaneously in structural modeling, the current study examines the specific associations between latent components of $\mathrm{EF}$ and RA/PA, while accounting for shared variance between RA/PA.

Consistent with Friedman and colleagues (2008; 2011; Miyake \& Friedman, 2012), it was expected that the nested, bifactor model of EF would fit the data well. The hypothesized nested model consists of three factors: a "Common EF" factor, accounting for 
shared variance across EF tasks and thus encompassing variance related to Inhibition; a "Monitoring-specific" factor, accounting for variance unique to scores tapping the ability to track and appraise incoming task information and update information in working memory appropriately; and a "Conceptual Flexibility-specific" factor, accounting for variance unique to scores tapping the ability to shift between tasks. Because RA is considered to be an impulsive response to provocation (e.g., Berkowitz, 1993), and research indicates it is associated with decreased levels of inhibition (e.g., Ellis et al., 2009), it was hypothesized that RA will be uniquely negatively associated with the Common EF factor, as it encompasses variance related to inhibition. Given the above-reviewed literature suggesting certain antisocial and aggressive behaviors that require higher levels of planning and deliberation may be associated with increased levels of EF (Barker et al., 2007; Raine et al., 1998), it was hypothesized that PA will be uniquely associated with higher levels of specific components of EF. However, given that very few studies have considered components of EF in relation to PA, hypotheses for PA's unique associations are tentatively proposed. Specifically, Barker et al. (2007) found theft to be positively associated with tasks tapping monitoring and conceptual flexibility. Similar to theft, PA theoretically requires the ability to maintain and update strategies in the service of goal attainment. As such, it was hypothesized that the Monitoring-specific and Conceptual Flexibility-specific EF would be uniquely positively associated with PA. 


\section{METHOD}

\subsection{Participants}

Data were drawn from a racially diverse sample of 384 undergraduate participants, aged 18-52 years $\left(M_{\text {age }}=20.9, S D=4.9 ; 57 \%\right.$ female $)$, who participated in a larger study of cognitive and personality factors contributing to individual differences in behavior among college students (see Hecht \& Latzman, 2015). Of the participants, $45.6 \%$ self identified as Black, $30.5 \%$ as White, $11.2 \%$ as Asian/Asian-American, $8.1 \%$ as other. All procedures were approved by the university's Institutional Review Board.

Participants were recruited using an online recruitment system through the university. Participants came into the laboratory for a 2-hour data collection session. Upon arrival to the laboratory, participants reviewed and signed the consent form under the direction of a research assistant, and completed the assessments. Participants were compensated with course credit via the online system.

\subsection{Measures}

\subsubsection{Delis Kaplan Executive Functioning System (D-KEFS)}

The Delis-Kaplan Executive Function System (D-KEFS; Delis, Kaplan, \& Kramer, 2001) is a standardized assessment of executive function. The D-KEFS was standardized on a nationally representative, stratified sample of nonclinical children, adolescents, and adults, ages 8 to 89 years. The D-KEFS has research support for its general validity and internal consistency reliability (Delis, Kramer, Kaplan, \& Holdnack, 2004), as well as test-retest reliability (Homack, Lee, \& Riccio, 2005).

As noted previously, recent factor analytic work (Latzman \& Markon, 2010) has found that D-KEFS individual achievement scores can be reduced to three components: Conceptual 
Flexibility, Monitoring, and Inhibition. These three empirically-derived aspects of EF have been shown to be differentially associated with other outcomes of interest (e.g., academic achievement; Latzman, Elkovitch, Young, \& Clark, 2010). Based on previous factor analytic work (Latzman \& Markon, 2010), the following D-KEFS tasks were included in the current study:

(1) Trail Making Test, a measure of attention, concentration, resistance to distraction, and cognitive flexibility, which involves connecting sets of dots as rapidly as possible while still maintaining accuracy and adhering to rules;

(2) Verbal Fluency Test, a measure of letter fluency, category fluency, and category switching, which requires speeded lexical production and automatic lexical access and reflects efficient lexical organization;

(3) Color-Word Interference Test, which involves rapidly naming colored words according to a set of rules, assesses selective or focused attention, and the ability to shift from one perceptual set to another as test requirements change as well as the ability to inhibit inappropriate responding; and

(4) Sorting Test, a measure of conceptual flexibility and set shifting, which involves sorting cards into groups according to a set of rules, or identifying the categories of pre-sorted cards.

These tasks were chosen as they have been shown to evidence the highest loadings on EF components (Inhibition, Monitoring, and Conceptual Flexibility; Latzman \& Markon, 2010). Specifically, using Exploratory Factor Analysis (EFA), Latzman \& Markon (2010) demonstrated that Conceptual Flexibility is best reflected by all three scores from the Sorting Test: free sort, free sort description, and sort recognition; Monitoring is reflected by the two category switching 
scores from the Verbal Fluency tests; and Inhibition is reflected by the inhibition and inhibition/switching scores from the Color-Word Test in addition to the Trail Making Test. Given that these tasks evidenced the highest factor loadings, it was assumed they tasks would adequately measure the unity and diversity of EF in the current study. Standard scores from each task were included in analyses.

\subsubsection{Reactive-Proactive Aggression Questionnaire}

The Reactive-Proactive Aggression Questionnaire (RPQ; Raine et al., 2006) is a 23-item measure with two scales: Reactive Aggression (RA) and Proactive Aggression (PA). Participants respond to items using a 3-point scale (Never; Sometimes; Often) to indicate how often they have engaged in various reactively-aggressive and proactively-aggressive behaviors. Example Proactive and Reactive items include, respectively: "Had fights with others to show who was on top," and "Gotten angry when others threatened you." Each item is rated as 0 (never), 1 (sometimes), or 2 (often) for frequency of occurrence. The RPQ demonstrates adequate reliability, with internal consistencies ranging from .86 for PA to .84 for RA (Raine et al., 2006). As reported previously, (Hecht \& Latzman, 2015), in the current sample, internal consistencies were .82 for RA and .81 for PA.

\subsection{Analyses}

Descriptive statistics were calculated for all variables. Next, zero-order correlations between D-KEFS scaled scores and RA/PA were calculated. In addition to raw (original) RA and PA scores, because RA and PA are often highly correlated (Poulin \& Boivin, 2000), and consistent with previous research (i.e., Cima \& Raine, 2009; Hecht \& Latzman, 2015; Hecht et al., in press), residualized RA and PA scores were saved to index "pure" RA and PA independent 
of each other. Specifically, RA was regressed on PA and the standardized residual was saved, and vice versa.

To examine for factorability, zero-order correlations were conducted among EF scores. All items were significantly correlated, indicating that each item shared variance with other items. Next, a measurement model was specified to confirm the nested, bifactor model of EF fit the data well. All structural analyses were completed using Mplus 7 (Muthen \& Muthen, 19982012). As described earlier, the EF measurement model was a nested bifactor model consistent with recent CFA studies by Friedman and colleagues (2008; 2011; Miyake \& Friedman, 2012). In the model, three components of EF were specified to fit the data (see Figure 1): Common-EF, Monitoring specific-EF, and Conceptual Flexibility-specific EF. All eight D-KEFS scores were set to load on the Common EF factor. In addition, the two scores from the Verbal Fluency Task (Category Switching condition) were set to load on the Monitoring-specific factor, and the three scores from the Card Sorting Task (Free Sort and Sort Recognition conditions) were set to load on the Conceptual Flexibility-specific factor. To examine the fit of this nested, bifactor model, multiple fit indices were considered, including chi-square, Root Mean Square Error of Approximation (RMSEA), Comparative Fit Index (CFI), and Standardized Root Mean Square Residual (SRMR).

Finally, structural equation modeling (SEM) was conducted to examine the associations between latent EF components and RA/PA. First, parcels were created as indicators of RA and PA. This approach was chosen in order to optimize power, as the RPQ consists of 23 items. Specifically, the use of parcels rather than individual items to estimate latent RA and PA results in a decreased number of observed variables, thereby increasing power (Little et al., 2002). RA and PA were each measured by three parcels computed from the average of multiple items from 
their respective scales. To ensure parcels were balanced indicators of their respective construct, item-total correlations were first conducted between items from each scale and the respective total score. Item to construct balancing was used to select items for each parcel so that low, moderate, and high indicators were equally represented across parcels (Little, Cunningham, \& Sharer, 2002). The resulting parcels each consisted of 2-3 items.

A structural equation model was then specified in which RA and PA were regressed on the components of EF from the nested, bifactor measurement model, as well as the demographic covariates of age, gender (dummy coded as female $=1$, male $=0$ ), and race (dummy coded as white $=1$, non-white $=0$ ). Again, to examine model fit, multiple fit indices were considered, including chi-square, Root Mean Square Error of Approximation (RMSEA), Comparative Fit Index (CFI), and Standardized Root Mean Square Residual (SRMR). 


\section{RESULTS}

\subsection{Bivariate Correlations}

Bivariate correlations between demographic variables, D-KEFS scaled scores, and both raw and residual RA/PA are shown in Table 1. With regard to demographics, both raw and residual PA were significantly negatively associated with gender $(r=-.23, p<.01 ; r=-.25, p<$ .01 , respectively), indicating that being female was associated with lower levels of PA, whereas being male was associated with higher levels. No other significant associations emerged between RA/PA and demographic variables.

With regard to associations between EF and subtypes of aggression, the pattern of correlations between D-KEFS scores and aggression was largely consistent for raw and residual RA/PA. Raw PA was not significantly associated with any of the D-KEFS variables, whereas raw RA was significantly negatively associated with both TMT Condition 4 and CW Condition 3 ( $r=-.13, p<.05 ; r=-.24, p<.05$, respectively). Similarly, residual RA was again significantly negatively associated with both TMT Condition 4 and CW Condition $3(r=-.10, p<.05 ; r=-$ $.15, p<.01$, respectively); whereas residual PA emerged as significantly positively associated with CW Condition $3(r=.29, p<.01)$. Overall, correlations between the D-KEFS scores and RA/PA (both raw and residual) were quite low, indicating each individual core accounted for very little variance in aggression. This highlights one of the downfalls of using single task indicators of EF, and underscores the importance of a latent variable approach when examining EF in relation to external constructs. 
Table 1. Bivariate correlations among covariates, D-KEFS scaled scores, and raw and residual RA and PA.

\begin{tabular}{|c|c|c|c|c|}
\hline & \multicolumn{2}{|c|}{ Raw Scores } & \multicolumn{2}{|c|}{ Residual Scores } \\
\hline & PA & RA & PA & RA \\
\hline \multicolumn{5}{|l|}{ Covariates } \\
\hline Age & -0.08 & -0.08 & -0.05 & -0.04 \\
\hline Race (non-white $=0$, white $=1$ ) & 0.00 & -0.03 & 0.02 & -0.04 \\
\hline Gender $($ male $=0 ;$ female $=1)$ & $-0.23 * *$ & -0.05 & $-.25 * *$ & 0.09 \\
\hline \multicolumn{5}{|l|}{ D-KEFS Scaled Scores } \\
\hline TMT Condition 4 & -0.07 & $-0.13 *$ & 0.00 & $-.10^{*}$ \\
\hline CW Condition 3 & -0.03 & $-0.14 *$ & $0.29 * *$ & $-0.15 * *$ \\
\hline CW Condition 4 & -0.01 & -0.05 & 0.01 & -0.05 \\
\hline VF Category Switching Total Correct & 0.03 & -0.04 & 0.06 & -0.07 \\
\hline VF Category Switching Accuracy & 0.06 & 0.00 & 0.07 & -0.04 \\
\hline ST Condition 1 Correct Sorts & 0.08 & 0.10 & 0.03 & 0.07 \\
\hline ST Condition 1 Description & 0.06 & 0.07 & 0.03 & 0.04 \\
\hline ST Condition 2 Recognition & -0.10 & -0.07 & -0.07 & -0.02 \\
\hline
\end{tabular}

Note. ${ }^{*} p<.05 ; * * p<.01$

\subsection{Nested bifactor model of EF}

To confirm the appropriateness of using the nested bifactor model of EF with the DKEFS tasks, a measurement model was fitted. As described above, in this nested, bifactor model, all D-KEFS standard scores were set to load on the Common-EF factor; the two scores from the 
Verbal Fluency task were set to load on the Monitoring-specific factor, and the three scores from the Card Sorting Task were set to load on the Conceptual Flexibility-specific factor. As can be seen in Figure 1, all items loaded significantly on their respective factors. Although the chisquare test of model fit was significant $(p<.01)$, the remaining fit indices were favorable $(\mathrm{SRMR}<.10, \mathrm{CFI}>$.95; RMSEA $<.10$; Klein, 2011), indicating this model fit the data well (see Table 2). The magnitude of the factor loadings ranged from .23 to .76 for Common EF (with the highest factor loadings demonstrated by the two scores from the Color-Word Interference Task), .92 to .94 for Monitoring-specific EF, and .56- to .93 for Conceptual Flexibility-specific EF.

Table 2. Fit Indices for the bifactor and structural models.

\begin{tabular}{lcccc} 
Model & $\mathrm{X}_{\mathrm{M}}{ }_{\mathrm{M}}(d f)$ & CFI & SRMR & $\begin{array}{c}\text { RMSEA } \\
{[90 \% \mathrm{CI}]}\end{array}$ \\
\hline Nested Bifactor Model & $35.33^{* *}(17)$ & .99 & .04 & $.05[.03-.08]$ \\
Structural Model & $231.45^{* *}(102)$ & .96 & .07 & $.06[.05-.07]$ \\
\hline
\end{tabular}

Note: $N=384 .{ }^{* *} p<.01$. CFI $=$ Comparative Fit Index; SRMR $=$ Standardized Root Meet Square Residual; RMSEA = Root Mean Square Error of Approximation. 
Figure 1. Measurement model depicting nested, bifactor model of EF.

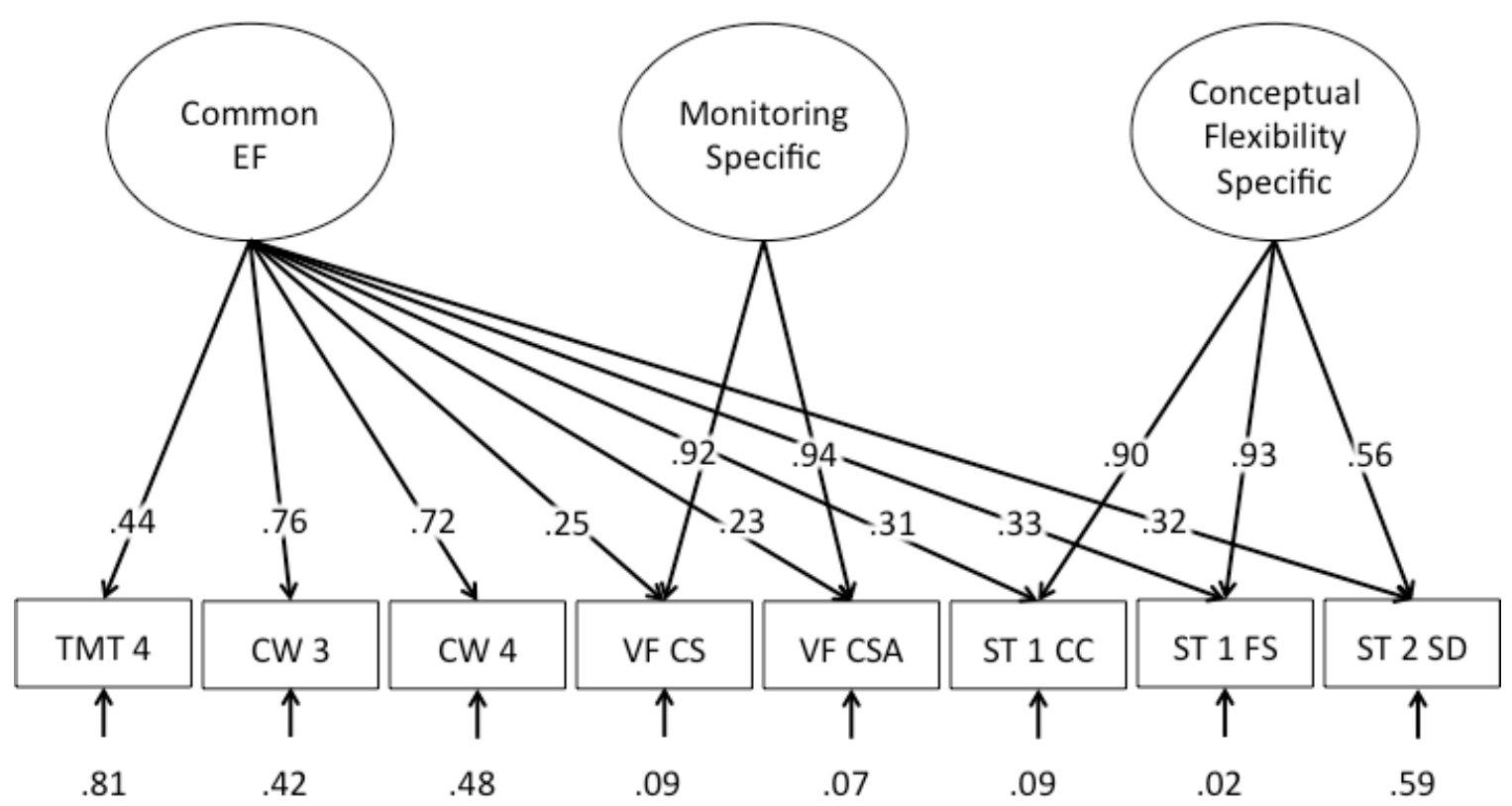

Note. $N=384 . \chi^{2}(17)=35.33, p<.01 ; \mathrm{SRMR}=.04 ; \mathrm{CFI}=.99 ; \mathrm{RMSEA}=.05$. Latent factors of $\mathrm{EF}$ are indicated by standardized D-KEFS scores. Numbers on paths between indicators and EF components represent standardized factor loadings; all factor loadings are significant. Numbers on arrows pointing to each indicator represent standardized residual variances; all residual variances are significant with the exception of those in italics. TMT $4=$ Trail Making Test, Condition 4; CW 3 = Color Word Interference Task, Condition 3; CW $4=$ Color Word Interference Task, Condition 4; VF CS = Verbal Fluency, Category Switching Score; VF CSA = Verbal Fluency, Category Switching Accuracy; ST 1 CC = Card Sorting Test, Confirmed Correct Sorts; ST 1 FS = Card Sorting Test, Free Sort Description Score; ST 2 SD = Card Sorting Test Sort Recognition Description Score.

\subsection{Structural equation modeling}

Finally, structural equation modeling was conducted to examine the associations between RA/PA and components of EF. EF was modeled according to the nested bifactor model described above, with latent RA and PA (modeled from their respective parcels) regressed on the Common, Monitoring-specific, and Conceptual Flexibility-specific EF factors; as well as age, race, and gender as covariates. As illustrated in Table 2, this model fit the data well $\left(\chi^{2}(102)=\right.$ $231.45, p<.01 ; \mathrm{SRMR}=.07 ; \mathrm{CFI}=.96 ; \mathrm{RMSEA}=.06$ ). Only PA emerged as significantly 
associated with any of the covariates; specifically, PA was significantly negatively associated with gender $(\beta=-.26, p<.01)$ as well as race $(\beta=-.21, p<.01)$, indicating that being female and being white were both associated with lower levels of PA. Consistent with previous research (e.g., Hecht \& Latzman, 2015; Hecht et al., in press; Raine et al., 1996; Poulin \& Boivin, 2000), latent RA and PA were significantly positively associated $(\beta=.72, p<.01)$. As shown in Figure 2 , PA was significantly explained by Monitoring $(\beta=.16, p<.01)$, but was not significantly explained by Inhibition $(\beta=-.01, p=.88)$ or Conceptual Flexibility $(\beta=.09, p=.13)$. RA was explained by Conceptual Flexibility $(\beta=.15, p<.02)$, Inhibition (although the association did not quite reach significance; $\beta=-.14, p=.05$ ), and was not significantly associated with Monitoring $(\beta=.04, p=.48)$. 
Figure 2. Structural model depicting latent components of EF and their association with latent RA and PA.

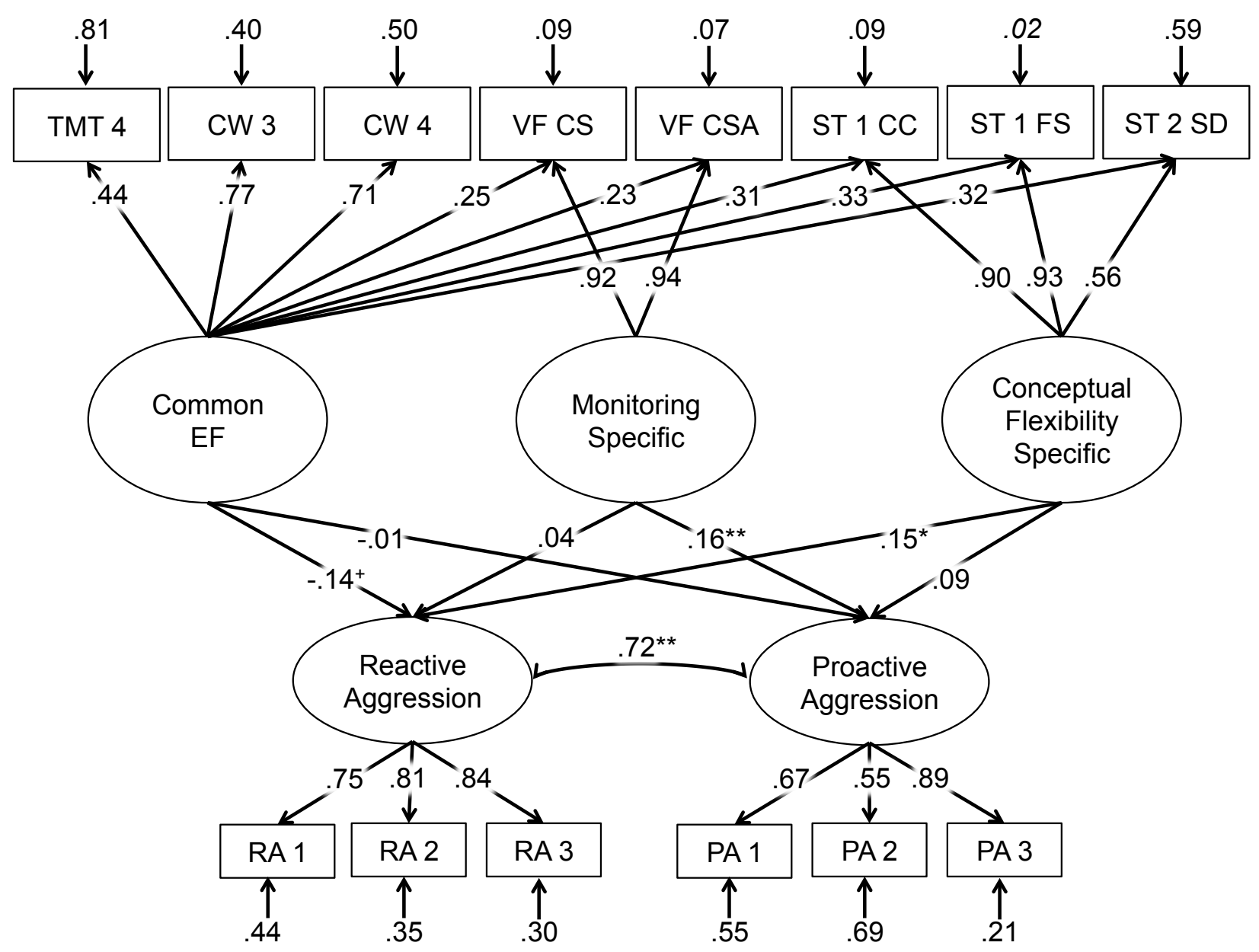

Note. $N=384$. Latent components of EF are indicated by standardized D-KEFS scores. Latent RA and PA are indicated by parcels created from items on the RPQ. Numbers on paths between indicators and latent variables represent standardized factor loadings; all factor loadings are significant. Numbers on arrows pointing to each indicator represent standardized residual variances; all residual variances are significant with the exception of those in italics. Numbers between latent variables represent standardized betas; ${ }^{*} p<.01,{ }^{*} p<.05,{ }^{+} p=.05$. RA $=$ Reactive Aggression; PA = Proactive Aggression; TMT 4 = Trail Making Test, Condition 4; CW 3 = Color Word Interference Task, Condition 3; CW 4 = Color Word Interference Task, Condition 4; VF CS = Verbal Fluency, Category Switching Score; VF CSA = Verbal Fluency, Category Switching Accuracy; ST 1 CC = Card Sorting Test, Confirmed Correct Sorts; ST 1 FS $=$ Card Sorting Test, Free Sort Description Score; ST 2 SD = Card Sorting Test Sort Recognition Description Score. 


\section{DISCUSSION}

A large body of literature confirms the importance of EF in the explanation of general aggression (e.g., Giancola, 1995; Morgan \& Lilienfeld, 2000; Ogilvie et al., 2011; Seguin, 2009; Seguin \& Zelazo, 2005); however, the precise nature of this association is poorly understood. Specifically, while a majority of this literature reveals strong associations between deficits in EF and the engagement in aggressive behaviors, a smaller body of literature suggests some aggressive behaviors are associated with relatively higher levels of performance on tasks of EF (e.g., Barker et al., 2007; Raine et al., 1998). There are two primary limitations that potentially contribute to these equivocal findings. First, the vast majority of this literature has utilized conceptualizations of aggression that lack specificity. Aggression is a broad, heterogeneous construct that can be broken down into meaningful subtypes, which may evidence differential associations with components of EF. When the lower-order structure of aggression is not taken into account, these potential differential associations may be overlooked. A second limitation obfuscating conclusions stems from the use of similarly over-simplified conceptualizations of EF that lack specificity. Much of this research conceptualizes EF as a single, broad construct (e.g., Giancola et al., 1996), and/or utilizes single task indicators of EF (e.g., Ellis et al. 2009; Stanford, Greve, \& Gerstle, 1997). However, recent theoretical and empirical developments reveal that EF is comprised of separable, but related components (e.g., Miyake et al., 2000) that cannot be adequately teased apart through the use of any one single task. Taken together, these findings suggest that research failing to account for the unity and diversity of EF through measurement and analysis is at risk of overlooking nuances in its associations with external constructs. Given these limitations in the existing literature, in the current study, the nuanced associations between EF and subtypes of aggression were explored 
through a latent variable approach. First, the appropriateness of using a nested bifactor model of EF was confirmed; and second, this bifactor model of EF was used to examine the specific associations between components of EF and RA and PA. Results revealed components of EF are differentially associated with RA and PA, such that impulsive, provoked aggression is associated with lower levels of goal-oriented inhibition and higher levels of flexibility, whereas planned, goal-oriented aggression is associated with higher levels of working memory. Thus, findings from the current study underscore the importance of considering the multidimensional nature of EF as well as aggression when examining their associations with external constructs of interest.

\subsection{Nested, bi-factor model of EF}

Before examining the contribution of components of EF to subtypes of aggression, it was first necessary to confirm the appropriateness of a nested, bifactor model of EF using traditional neuropsychology-based tasks of EF. Initial research on the factor structure of EF revealed three separate yet related components (e.g., Miyake et. al, 2000) of Inhibition, Monitoring, and Conceptual Flexibility (Latzman \& Markon, 2010), and this general factor structure has been observed across various samples using various indicators of EF (e.g., Friedman et al., 2011; Latzman \& Markon, 2010; Rose, Feldman, \& Jankowski, 2011; Vaughan \& Giovanello, 2010). In recent years, this framework has been further developed (for a comprehensive review, see Miyake \& Friedman, 2012) and in the current conceptualization, the components of EF are best represented in a nested, bifactor model. In this framework, the unity of EF is reflected by a Common EF component that encompasses variance common across all three EFs (Inhibition, Monitoring, and Conceptual Flexibility), and the diversity of EF is reflected by Monitoringspecific and Conceptual Flexibility-specific factors that encompass the variance that is unique to the respective ability (Friedman et al., 2008; 2011; Miyake \& Friedman, 2012). Although this 
nested, bifactor model has gained considerable traction in recent years (e.g., Miyake \& Friedman, 2012), it has solely been considered within the cognitive psychology domain, using computer-based tasks as indicators of EF. The current study thus serves to extend these findings into the clinical neuropsychology domain, as it represents the first study to date to leverage traditional neuropsychology-based tasks of EF within this framework.

Consistent with findings from the cognitive-psychology domain (e.g. Friedman et al., 2008; 2011; Miyake \& Friedman, 2012), results from the current study revealed that a nested, bifactor model of EF is appropriate using traditional clinical neuropsychology data. The advantage of using this data-driven, latent variable approach rather than creating composite $\mathrm{EF}$ scores from several tasks is illustrated by the factor loadings and residual variances. Specifically, factor loadings across components ranged from .23 to .94 , with residual variances (the variance unrelated to the target component of EF) ranging from .02 to .81. Thus, each DKEFS task included variance that was both related and unrelated to the target component of EF, underscoring the strength of a latent variable approach which reduces the amount of error in each factor (Bollen, 2014). The advantage of the latent variable approach is also underscored by the low bivariate correlations observed between specific D-KEFS scores and raw and residual RA/PA. Specifically, such low correlations indicate each individual D-KEFS task explains very little variance in RA and PA; highlighting the importance of using multiple task indicators to model the variance common across tasks as latent components of EF.

In terms of the unity of EF, factor loadings for the Common EF component ranged from .23-.76, indicating that the contribution of each D-KEFS score was rather variable. The highest contribution was from performance on two aspects of the Color-Word Interference task, a slightly-modified Stroop task, which is considered a classic indicator of inhibition (e.g., Miyake, 
2000); followed by the switching condition of the Trail-Making Task, which places demands on inhibitory abilities by requiring the inhibition of one task (connecting numbers in order) while switching mental sets (connecting letters in order). Importantly, these were also the three tasks evidencing the highest factor loadings on the Inhibition component in Latzman and Markon's (2010) EFA investigation of the factor structure of the D-KEFS. The remaining Common EF tasks evidenced factor loadings ranging from .23-.33, indicating that each of these tasks also included substantial variance related to inhibition. Thus, the Common EF component is comprised of abilities important for performance on all of the D-KEFS tasks, with the largest contribution from inhibition-related abilities. Taken together, results indicate the Common EF variable largely reflects an ability to control or inhibit a pre-potent response in the service of goal-oriented action, which also involves the ability to attend to incoming and potentially competing task information and shift action accordingly. This is in line research utilizing computer-based tasks of EF (Friedman et al., 2008; 2011; Miyake \& Friedman, 2012), in which the Common EF component is interpreted as encompassing the basic abilities required for all aspects of EF: the ability to actively maintain goals and use task-relevant information to engage inhibition as well as other lower-level processing toward successful goal completion. Indeed, this conceptualization of Common EF is consistent with views of goal-directed inhibitory control abilities (Munakata et al., 2011), and is thus the perspective assumed from the current results.

In this framework, the diversity of EF is represented by the Monitoring- and Conceptual Flexibility-specific components of EF, which reflect variance from performance on their respective indicators after the variance attributable to Common EF has been removed. In the current study, the Monitoring-Specific component evidenced the highest factor loadings (ranging from .92-.94), indicating that in this sample, although the variance associated with Verbal 
Fluency performance contributed significantly to the Common EF component, it is better explained by the Monitoring-Specific component. Thus, in the current study, Monitoring-specific EF largely encompassed variance that was specific to the ability to track and appraise incoming task information, filter information that is relevant to the task at hand, and update this information in working memory appropriately. This is largely consistent with Miyake \& Friedman's (2012) speculation, based on computerized EF tasks, that this component is important for effectively filtering information and retrieving information from long-term storage. Finally, the Conceptual Flexibility-specific component also evidenced high factor loadings (ranging from .56-.93), reflecting substantial variance from performance on three aspects of the Card Sorting Task. This task requires the ability to actively switch between engaging verbal and perceptual abilities in order to produce and recognize various card sorts; thus, this component encompassed variance specific to the ability to switch flexibly between tasks or mental sets. Such an interpretation is largely consistent with Miyake \& Friedman's (2012) understanding of this component as reflecting flexibility in transitioning between task sets.

\subsection{Associations between components of EF and RA/PA}

The primary advantage of a latent variable approach to representing the unity and diversity of $\mathrm{EF}$ is that it encompasses the multidimensional nature of the construct, and also helps to alleviate the task impurity problem through the use of multiple task indicators of each component of EF (e.g., Miyake et al; Washburn et al., 2015). This benefit allowed for a more precise examination of the associations between components of EF and $\mathrm{RA} / \mathrm{PA}$ than in previous studies, revealing specific associations between components of EF and RA and PA. Such results support the notion that although RA and PA are overlapping constructs, they do exhibit important distinct correlates (e.g., Ellis et al., 2009; Fite et al., 2007; McAuliffe et al., 2006), 
suggesting these subtypes of aggression may arise from differing cognitive processes, with potentially unique neuroanatomical correlates.

In the current study, the Common EF factor emerged as marginally significantly associated with RA $(\beta=-.14, p=.05)$, and was not associated with PA. As this component represents EF variance common across all D-KEFS tasks, and represents goal-directed inhibitory abilities, it appears that increased levels of goal-directed inhibition may be associated with lower levels of impulsive, reactionary aggression. Although this association did not reach the traditional, dichotomous $\mathrm{p}<.05$ level of significance, the implication is consistent with theoretical expectations. Given that a primary distinction between RA and PA is the degree of impulsivity underlying the behavior (Berkowitz, 1993; Dodge, 1991; Raine et al., 2006), it would follow that increased inhibitory abilities might contribute to decreased RA. Indeed, research has found RA to be associated with decreased inhibitory abilities, such as performance on a Stroop task (Ellis et al., 2009), and on the WCST (Stanford, Greve, \& Gerstle, 1997), which has been shown to involve multiple component processes of EF including inhibition (Miyake et al., 2000). Moreover, Giancola et al. (1996) modeled a single latent EF factor from a variety of EF tasks, and found that it was negatively associated with RA in boys with a family history of substance abuse. Although Giancola and colleagues conceptualized EF as a unidimensional construct, the tasks that evidenced positive factor loadings on the overarching EF factor all required a high degree of goal-oriented inhibition (a maze task, a vigilance task, and a forbidden toy task). Taken together, results confirm the negative association between goal-directed inhibitory abilities and RA. Nevertheless, despite the fact that the current borderline significant results converge with evidence from the above-reviewed studies, it will be important for future research to both replicate and explicate this finding. To facilitate prevention and intervention 
efforts, it will be important to examine the specific mechanisms by which EF abilities contribute to decreased provoked aggression. For example, it is possible that increased goal-directed inhibition abilities are associated with lower levels of impulsive aggression through an increased ability to regulate emotions, as inhibitory control on a stop-signal task has been associated with increased success in emotion regulation (Tabibnia et al., 2011).

In addition to its negative association with Common EF, RA was significantly positively associated with the Conceptual Flexibility-Specific component of EF. This is unexpected, as the ability to switch flexibly between tasks or mental sets would theoretically be unrelated or negatively associated with RA. Given RA is an impulsive-aggressive response to provocation (e.g., Berkowitz, 1993; Dodge, 1991), it would seem counterintuitive that an increased ability to adjust behavior would be related to increased levels of provoked aggression. There are several potential explanations for this surprising finding. First, the Conceptual Flexibility-specific component represents variance that is unique to performance on the three scores that comprise this component; in other words, it represents the variance that remains after Common EF (largely comprised of goal-oriented inhibitory abilities) is removed. In contrast to inhibition, which can be thought of as rigidly resisting action, flexibility requires the ability to shift quickly, to adjust to variability in task demands and changing contingencies. It is possible that once this inhibitionrelated variance is removed by the Common-EF component, the variance in the tasks encompassed by Conceptual Flexibility-specific component reflects flexibility in the absence of inhibition, or a liability toward reactivity. Indeed, RA has been conceptualized as emotionallydriven (e.g., Berkowitz, 1993; Dodge, 1991), and research confirms its association with increased emotion dysregulation (Marsee \& Frick, 2007; Shields \& Cicchetti, 1998; Vitaro et al., 2002). 
Research examining the association between Conceptual-Flexibility-specific abilities and impulsivity-related constructs also helps to contextualize the surprising positive association between Conceptual Flexibility-specific EF and RA found in the current study. Specifically, Friedman and colleagues (2007) demonstrated that shifting abilities were positively associated with attention problems throughout adolescence. Similarly, the ability to shift attention has also been associated with decreased levels of response inhibition (Jones, Rothbart, \& Posner, 2003). Moreover, in a longitudinal study, Friedman et al. (2011) revealed that youth with higher levels of self-restraint evidenced increased levels of Common-EF and decreased levels of Conceptual Flexibility-specific EF two years later. Taken together, it appears that common EF and shiftingspecific abilities sometimes evidence surprising opposing patterns of associations with external constructs (Miyake \& Friedman, 2012), and particularly those related to behavioral control (Herd et al., 2014). Indeed, it has been theorized that goal-oriented action is regulated by opposing constraining forces (Goschke, 2000): whereas goal completion requires stability in maintaining that goal (e.g., inhibition), it also requires an ability to adjust strategy according to changing demands (e.g., flexibility). In other words, successfully completing a task requiring high levels of the Conceptual Flexibility-specific component of EF involves simultaneously carrying out two opposing processes - inhibiting the previous mental set while also holding it in mind and engaging a new task set (Davison, Amso, Anderson, \& Diamond, 2006). In sum, decreased inhibitory abilities may "free up" flexibility, and vice versa. Thus, the decreased inhibition inherent in RA may allow for increased flexibility, which could help to explain the positive association between Conceptual Flexibility-specific EF and RA in the current study. Nevertheless, this interpretation is tentative, and given that the significant positive association between Conceptual Flexibility-specific EF and RA was unexpected, it requires further research. 
This is particularly important because the Conceptual Flexibility-specific component in the current study is comprised entirely of variance from multiple parts of a single task. Specifically, variance related to performance from three parts of the Card Sorting Test contributed to this component: the number of confirmed correct card sorts from the Free Sorting condition, the score for the description of the sorts in the Free Sorting condition, and the score for recognizing the sorts in the Sort Recognition condition. Although the latent-variable approach in the current study reduces measurement error compared to the use of individual tasks (Bollen, 2014), it does not take into account potential shared method variance when the target component of EF is comprised of multiple indicators from the same task. Thus, additional studies utilizing multiple task indicators from various tasks will help to clarify what is reflected in the Conceptual Flexibility-specific component.

Given that few studies have examined associations between EF and PA, hypotheses regarding the specific associations between components of EF and PA were more cautious. Although it was tentatively hypothesized that both Conceptual Flexibility-specific and Monitoring-specific EF would be uniquely positively associated with PA, only Monitoring emerged as significant $(\beta=.16, p<.01)$. Thus, the component of EF most relevant to planned, goal-directed aggression is the ability to monitor incoming information for relevance for the task at hand and then appropriately update online information with new, more relevant information. This is consistent with research indicating that antisocial behaviors requiring increased levels of planning and premeditation are associated with higher levels of EF, particularly monitoring- and conceptual-flexibility related abilities (Barker et al., 2007). The lack of association between PA and Conceptual Flexibility-specific EF was thus somewhat unexpected. As noted previously, Conceptual Flexibility-specific EF represents the variance in performance on its respective tasks 
once the Common-EF variance has been extracted. It is possible that once this inhibition-related variance is removed, the variance unique to the ability to flexibly shift between mental sets and adjust action accordingly may not be as relevant to planned, goal-directed acts of aggression.

The distinct associations observed in the current study add to existing literature that provides evidence of external constructs that distinguish between RA and PA (e.g., Ellis et al., 2009; Fite et al., 2007; Hecht \& Latzman, 2015; Hecht et al., in press; McAuliffe et al., 2006; Miller \& Lynam, 2006). The specific pattern of associations revealed within this study indicate that RA and PA are characterized by unique cognitive processes. That is, whereas RA is a stimulus-driven, disinhibited response, PA is driven by top-down control in the service of goal attainment. Such results confirm the construct validity of RA and PA as unique but overlapping constructs, and thus provide both psychometric and psychological clarification of these constructs. Similarly, results help to confirm the validity of the nested, bi-factor model of EF, and provide clarification of what is represented by the specific components within this model.

In addition to clarifying the specific associations between components of EF and RA/PA, results from the current study have broader implications for our understanding of these constructs, and the biological mechanisms that underlie them. Overall, results lend credence to the notion that RA and PA may arise from unique cognitive processes, which may be associated with unique brain regions. Indeed, recent neuroimaging research using the unity and diversity framework of EF indicates that the EF components also demonstrate common and unique neuroanatomical correlates (Collette et al., 2005; Sylvester et al., 2003). Specifically, using positron emission tomography (PET), Collete and colleagues (2005) demonstrated that all inhibition, monitoring, and shifting tasks activated common frontal and parietal regions, whereas unique areas of the frontal and/or posterior regions were activated by monitoring and shifting 
tasks specifically. Similarly, using functional magnetic resonance imaging (fMRI), Sylvester and colleagues (2003) illustrated that inhibition and switching tasks activate common (e.g., parietal cortical) as well as unique (e.g., superior parietal and frontopolar cortical) areas of the brain. Indeed, within a nested, bifactor framework of EF, it has been suggested that unique neural networks underlie Common EF and Conceptual Flexibility-specific EF, which may help to explain their curious pattern of opposing associations with external constructs (Herd et al., 2014). Taken together with results from the current study, it appears that although RA and PA are overlapping constructs, they may arise from distinct cognitive processes that implicate specific regions and/or networks within the brain.

The notion that RA and PA may arise from different brain-based mechanisms is further strengthened by research revealing that there are considerable genetic contributions underlying individual differences in the various latent components of EF (Friedman et al., 2008). In their twin study, Friedman and colleagues (2008) discovered that the unity of EF (represented by the variance common across EF tasks) is $99 \%$ heritable; whereas the diversity of EF or the updating and shifting-specific components were $56 \%$ and $42 \%$ heritable, respectively. In follow up analyses, the authors found that the genetic influence on EF components went over and above the genetic influence of intelligence, further underscoring the strength of EF's genetic contribution. When taken together with the current results, the genetic influence on EF components suggests that RA and PA may be associated with potentially unique underlying biological mechanisms. Thus, the current study lays the groundwork for future research to begin to consider the potentially unique pathways from biological, brain-based mechanisms to specific subtypes of aggressive behavior. 


\subsection{Strengths \& Limitations}

The current study possesses a number of strengths that contribute to an overall improvement over existing literature in this area. First, the latent variable approach in the current study improves upon previous literature, as observed variables are impure measures of their constructs. Through this approach, the variance common across multiple task indicators is leveraged to model the target latent variable, which results in a more pure or precise measure of the target variable (Bollen, 2014). This is an especially advantageous approach with regard to EF, as single tasks tapping EF abilities necessarily involve multiple lower levels processes, contributing to the "task impurity" problem described previously (e.g., Miyake et al., 2000; Washburn et al., 2015). In the current study, indicators of each target EF component were chosen based on a previous examination of the factor structure of the D-KEFS (Latzman \& Markon, 2010), resulting in each EF component representing variance that was common across its tasks indicators, thereby reducing variance in each component that is related to non-EF processes.

An additional strength of the current study was the use of a self-report measure of RA and PA, which was used to model latent RA/PA. This allowed access into the private motivations behind aggressive acts (Raine et al., 2006), and the latent variable approach allowed for a more pure measure of RA and PA than would be possible through observed variables (Bollen, 2014). Finally, the use of structural equation modeling approach in analyses allowed for the examination of the unique associations with RA and PA, independent of their overlapping variance.

Despite these strengths, the current study is not without its limitations. Given the crosssectional, correlational nature of these data, it will be important for longitudinal studies to prospectively examine the prediction of subtypes of aggression from components of executive 
functioning. Further, the use of an undergraduate sample may limit the generalizability of these findings, and potentially contributes to a restriction of range problem in that participants drawn from a university community arguably demonstrate stronger than average cognitive abilities and low levels of aggression. In addition, it is possible that general intelligence may impact the associations between components of EF and RA/PA, as both EF (e.g., Miyake et al., 2001; Engle et al., 1999) and aggression (e.g., Moffitt et al., 1993) have been associated with intelligence. As such, it will be important for future research to consider the effect of intelligence on these associations. Nevertheless, given that EF and intelligence are separate constructs, and components of EF demonstrate a genetic influence that goes beyond the influence of intelligence alone (e.g., Friedman et al., 2008), specific associations between components of EF and subtypes of aggression would likely still remain, above and beyond the influence of intelligence.

Moreover, although the latent variable approach employed in the current study represents a significant improvement upon previous research, both Conceptual Flexibility and Monitoring were comprised of variance from performance on single tasks. Specifically, Conceptual Flexibility was reflected by three scores from various parts of the Card Sorting Task, and Monitoring was reflected by two scores from the Verbal Fluency Task. While this is certainly an improvement over single-task indicators of EF, particularly given the latent variable approach, it is possible that the variance contributing to each EF component may include task-specific variance unrelated to the target EF component. This is especially a concern for Monitoring, which is modeled from only two scores, both of which are from the same task condition. Thus, it will be important for future research to increase both the number and variety of indicators for each component, to further alleviate the task impurity problem and contribute to increased precision in measuring the target EF components. Additionally, as noted previously, this is the 
first study to date to extend the nested, bifactor model of EF to more traditional neuropsychology-based EF tasks. Although this is a significant strength of this investigation, it will be important for future research to consider both cognitive as well as traditional neuropsychology-based EF tasks, as the use of both modalities would also contribute to alleviating the task impurity problem and reduce shared method variance.

\subsection{Conclusions}

In conclusion, limitations notwithstanding, the current study makes an important contribution to the existing literature by providing the most in-depth and comprehensive assessment to date of the nuanced associations between executive functioning and subtypes of aggression. By leveraging a latent variable framework of EF, a well-validated self-report measure of RA and PA, and employing a structural equation modeling analytic approach, the current study elucidated the unique associations between components of EF and RA and PA. Results revealed that impulsive, provoked aggression is explained by decreased goal-directed inhibitory abilities, and increased flexibility. In contrast, increased monitoring and updating abilities explain planned, goal-directed aggression. These findings underscore the importance of considering the multidimensional nature of EF, as well as the heterogeneity within aggression, rather than conceptualizing either as a single broad construct. The current findings have considerable implications for understanding the specific mechanisms that link cognitive functioning to antisocial behaviors. Indeed, the current results point to potentially unique brainbased pathways from aspects of executive functioning to specific subtypes of aggression, and thus reveal potential avenues through which to intervene. Overall, it appears that aggression may not arise from purely deficits in cognitive functioning - rather, aspects of EF may decrease the 
engagement in certain subtypes of aggression (e.g., goal-oriented inhibition), while others may contribute to tendencies toward specific subtypes of aggression (e.g., flexibility, monitoring). 


\section{REFERENCES}

Anderson, C. A., \& Bushman, B. J. (2002). Human aggression. Psychology, 53(1), 27. doi: 10.1146/annurev.psych.53.100901.135231

Archer, J. (2004). Sex differences in aggression in real-world settings: A meta-analytic review. Review of General Psychology, 8(4), 291-322. doi:10.1037/1089-2680.8.4.291

Bandura, A. (1978). Social learning theory of aggression. Journal of Communication, 28(3), 1229. doi:10.1111/j.1460-2466.1978.tb01621.x

Barker, E. D., Séguin, J. R., White, H. R., Bates, M. E., Lacourse, E., Carbonneau, R., \& Tremblay, R. E. (2007). Developmental trajectories of male physical violence and theft: relations to neurocognitive performance. Archives of General Psychiatry, 64(5), 592-599. doi:10.1001/archpsyc.64.5.592

Baron, R. A., \& Richardson, D. R. (1994). Human aggression (2nd ed.). New York, NY, US: Plenum Press.

Beauchaine, T. P., Neuhaus, E., Brenner, S. L., \& Gatzke-Kopp, L. (2008). Ten good reasons to consider biological processes in prevention and intervention research. Development and Psychopathology, 20(03), 745-774. DOI: 10.1017/S0954579408000369

Berkowitz, L. (1993). Aggression: Its causes, consequences, and control. New York, NY, England: Mcgraw-Hill Book Company.

Best, M., Williams, J. M., \& Coccaro, E. F. (2002). Evidence for a dysfunctional prefrontal circuit in patients with an impulsive aggressive disorder. Proceedings of the National Academy of Sciences, 99(12), 8448-8453. doi:10.1073/pnas.112604099

Blair, C., \& Ursache, A. (2011). A bidirectional model of executive functions and selfregulation. In K. D. Vohs, R. F. Baumeister (Eds.), Handbook of Self-Regulation: 
Research, Theory, and Applications (2nd ed.) (pp. 300-320). New York, NY, US: Guilford Press.

Blair, R. J. R. (2001). Neurocognitive models of aggression, the antisocial personality disorders, and psychopathy. Journal of Neurology, Neurosurgery \& Psychiatry, 71(6), 727-731. doi:10.1136/jnnp.71.6.727

Bollen, K. A. (2014). Structural equations with latent variables. John Wiley \& Sons.

Brendgen, M., Vitaro, F., Tremblay, R. E., \& Lavoie, F. (2001). Reactive and proactive aggression: Predictions to physical violence in different contexts and moderating effects of parental monitoring and caregiving behaviour. Journal of Abnormal Child Psychology, 29, 293-304. doi: 10.1023/A:1010305828208

Bridgett, D. J., Oddi, K. B., Laake, L. M., Murdock, K. W., \& Bachmann, M. N. (2013). Integrating and differentiating aspects of self-regulation: Effortful control, executive functioning, and links to negative affectivity. Emotion, 13(1), 47. doi: 10.1037/a0029536

Broidy, L. M., Nagin, D. S., Tremblay, R. E., Bates, J. E., Brame, B., Dodge, K. A., ... Vitaro, F. (2003). Developmental trajectories of childhood disruptive behaviors and adolescent delinquency: A six-site, cross-national study. Developmental Psychology, 39(2), 222245. doi:10.1037/0012-1649.39.2.222

Brower, M. C., \& Price, B. H. (2001). Neuropsychiatry of frontal lobe dysfunction in violent and criminal behaviour: A critical review. Journal Of Neurology, Neurosurgery \& Psychiatry, 71(6), 720-726. doi:10.1136/jnnp.71.6.720

Burke, J. D., Loeber, R., \& Birmaher, B. (2002). Oppositional defiant disorder and conduct disorder: a review of the past 10 years, Part II. Journal of the American Academy of Child and Adolescent Psychiatry, 41, 1275-1293. doi:10.1097/00004583-200211000-00009 
Bushman, B. J., \& Anderson, C. A. (2001). Is it time to pull the plug on hostile versus instrumental aggression dichotomy? Psychological review, 108(1), 273-279. doi:10.1037/0033-295x.108.1.273

Card, N. A., \& Little, T. D. (2006). Proactive and reactive aggression in childhood and adolescence: A meta-analysis of differential relations with psychosocial adjustment. International Journal of Behavioral Development, 30(5), 466-480. doi: $10.1177 / 0165025406071904$

Carlson, S. M., \& Moses, L. J. (2001). Individual differences in inhibitory control and children's theory of mind. Child Development, 72, 1032-1053. doi: 10.1111/1467-8624.00333

Cima, M., \& Raine, A. (2009). Distinct characteristics of psychopathy relate to different subtypes of aggression. Personality and Individual Differences, 47(8), 835-840. doi:10.1016/j.paid.2009.06.031

Cima, M., Tonnaer, F., \& Lobbestael, J. (2007). Moral emotions in predatory and impulsive offenders using implicit measures. Netherlands Journal of Psychology, 63, 144-155. doi:10.1007/bf03061076

Cohen, J. D., Forman, S. D., Braver, T. S., Casey, B. J., Servan-Schreiber, D., \& Noll, D. C. (1993). Activation of the prefrontal cortex in a nonspatial working memory task with functional MRI. Human Brain Mapping, 1(4), 293-304. doi:10.1002/hbm.460010407

Collette, F., Van der Linden, M., Laureys, S., Delfiore, G., Degueldre, C., Luxen, A., \& Salmon, E. (2005). Exploring the unity and diversity of the neural substrates of executive functioning. Human brain mapping, 25(4), 409-423. doi: 10.1002/hbm.20118 
Connor, D. F., Steingard, R. J., Cunningham, J. A., Anderson, J. J., \& Melonni, R. H. (2004). Proactive and reactive aggression in referred children and adolescents. American Journal of Orthopsychiatry, 74, 129-136. doi:10.1037/0002-9432.74.2.129

Crick, N. R., \& Dodge, K. A. (1994). A review and reformulation of social informationprocessing mechanisms in children's social adjustment. Psychological Bulletin, 115(1), 74. doi: 10.1037/0033-2909.115.1.74

Crick, N. R., \& Dodge, K. A. (1996). Social information-processing mechanisms in reactive and proactive aggression. Child Development, 67(3), 993-1002. doi:10.2307/1131875

Crick, N. R., \& Grotpeter, J. K. (1995). Relational Aggression, Gender, and Social-Psychological Adjustment. Child Development, 66(3), 710-722. doi:10.1111/j.14678624.1995.tb00900.x

Davidson, R. J., Putnam, K. M., \& Larson, C. L. (2000). Dysfunction in the neural circuitry of emotion regulation--a possible prelude to violence. Science, 289(5479), 591-594. doi:10.1126/science.289.5479.591

Davidson, M. C., Amso, D., Anderson, L. C., \& Diamond, A. (2006). Development of cognitive control and executive functions from 4 to 13 years: Evidence from manipulations of memory, inhibition, and task switching. Neuropsychologia, 44(11), 2037-2078. doi: 10.1016/j.neuropsychologia.2006.02.006

Delis, D. C., Kaplan, E., \& Kramer, J. (2001). Delis-Kaplan Executive Function System. San Antonio, TX: Psychological Corporation.

Delis, D. C., Kramer, J. H., Kaplan, E., \& Holdnack, J. (2004). Reliability and validity of the Delis-Kaplan Executive Function System: An update. Journal of the International Neuropsychological Society, 10, 301-303. doi:10.1017/s1355617704102191 
Denson, T. F. (2011). A social neuroscience perspective on the neurobiological bases of aggression. In P. R. Shaver, M. Mikulincer (Eds.), Human Aggression and Violence: Causes, Manifestations, and Consequences (pp. 105-120). Washington, DC, US: American Psychological Association. doi:10.1037/12346-006

Dodge, K. A. (1991). The structure and function of reactive and proactive aggression. In D. J. Pepler, K. H. Rubin (Eds.), The Development and Treatment of Childhood Aggression (pp. 201-218). Hillsdale, NJ, England: Lawrence Erlbaum Associates, Inc.

Dodge, K. A., \& Coie, J. D. (1987). Social-information-processing factors in reactive and proactive aggression in children's peer groups. Journal of Personality and Social Psychology, 53, 1146- 1158. doi: 10.1037/0022-3514.53.6.1146

Dodge, K. A., Lochman, J. E., Harnish, J. D., Bates, J. E., \& Pettit, G. S. (1997). Reactive and proactive aggression in school children and psychiatrically impaired chronically assaultive youth. Journal of Abnormal Psychology, 106(1), 37-51. doi:10.1037/0021$843 x .106 .1 .37$

Dodge, K. A., Lochman, J. E., Harnish, J. D., Bates, J. E., \& Pettit, G. S. (1997). Reactive and proactive aggression in school children and psychiatrically impaired chronically assaultive youth. Journal of Abnormal Psychology, 106, 37-51. doi:10.1037/0021$843 x .106 .1 .37$

Dodge, K.A., Coie, J.D., Pettit, G.S., \& Price, J.M. (1990). Peer status and aggression in boys' groups: Developmental and contextual analyses. Child Development, 61, 1289-1309. doi: $10.1111 / \mathrm{j} .1467-8624.1990 . t b 02862 . x$

Dolan, M., \& Anderson, I. M. (2002). Executive and memory function and its relationship to trait impulsivity and aggression in personality disordered offenders. The Journal of Forensic 
Psychiatry, 13(3), 503-526. doi: 10.1080/0958518021000019452

Egner, T., \& Hirsch, J. (2005). The neural correlates and functional integration of cognitive control in a Stroop task. Neuroimage, 24(2), 539-547. doi:10.1016/j.neuroimage.2004.09.007

Engle, R. W., Tuholski, S. W., Laughlin, J. E., \& Conway, A. R. (1999). Working memory, short-term memory, and general fluid intelligence: a latent-variable approach. Journal of experimental psychology: General, 128(3), 309.

Eisenberg, N., Hofer, C., \& Vaughan, J. (2007). Effortful control and its socioemotional consequences. In J. J. Gross (Ed.), Handbook of Emotion Regulation (pp. 287-306). New York, NY, US: Guilford Press.

Eisenberg, N., Spinrad, T. L., \& Eggum, N. D. (2010). Emotion-related self-regulation and its relation to children's maladjustment. Annual Review of Clinical Psychology, 6, 495. doi: 10.1146/annurev.clinpsy.121208.131208

Ellis, L. K., Rothbart, M. K., \& Posner, M. I. (2004). Individual differences in executive attention predict self-regulation and adolescent psychosocial behaviors. Annals of the New York Academy of Sciences, 1021, 337-340. doi: 10.1196/annals.1308.041

Ellis, M. L., Weiss, B., \& Lochman, J. E. (2009). Executive functions in children: Associations with aggressive behavior and appraisal processing. Journal of Abnormal Child Psychology, 37(7), 945-956. doi:10.1007/s10802-009-9321-5

Fite, P. J., Raine, A., Stouthamer-Loeber, M., Loeber, R., \& Pardini, D. A. (2010). Reactive and proactive aggression in adolescent males examining differential outcomes 10 years later in early adulthood. Criminal Justice and Behavior, 37(2), 141-157.

doi:10.1177/0093854809353051 
Fleming, K. A., Heintzelman, S. J., \& Bartholow, B. D. (2015). Specifying Associations Between Conscientiousness and Executive Functioning: Mental Set Shifting, Not Prepotent Response Inhibition or Working Memory Updating. Journal of personality. doi: 10.1111/jopy.12163

Frick, P. J., Cornell, A. H., Barry, C. T., Bodin, S. D., \& Dane, H. E. (2003). Callousunemotional traits and conduct problems in the prediction of conduct problem severity, aggression, and self- report of delinquency. Journal of Abnormal Child Psychology, 31, 457-470. doi:10.1007/s10648-005-5728-9

Friedman, N. P., Haberstick, B. C., Willcutt, E. G., Miyake, A., Young, S. E., Corley, R. P., \& Hewitt, J. K. (2007). Greater attention problems during childhood predict poorer executive functioning in late adolescence. Psychological Science, 18(10), 893-900. doi: 10.1111/j.1467-9280.2007.01997.x

Friedman, N. P., Miyake, A., Young, S. E., DeFries, J. C., Corley, R. P., \& Hewitt, J. K. (2008). Individual differences in executive functions are almost entirely genetic in origin. Journal of Experimental Psychology: General, 137(2), 201. doi: 10.1037/0096-3445.137.2.201

Friedman, N. P., Miyake, A., Robinson, J. L., \& Hewitt, J. K. (2011). Developmental trajectories in toddlers' self-restraint predict individual differences in executive functions 14 years later: a behavioral genetic analysis. Developmental psychology, 47(5), 1410. Doi: $10.1037 / \mathrm{a} 0023750$

Giancola, P. R. (1995). Evidence for dorsolateral and orbital prefrontal cortical involvement in the expression of aggressive behavior. Aggressive Behavior, 21(6), 431-450. doi: 10.1002/1098-2337(1995)21:6

Giancola, P. R., Martin, C. S., Tarter, R. E., Pelham, W. E., \& Moss, H. B. (1996). Executive 
cognitive functioning and aggressive behavior in preadolescent boys at high risk for substance abuse/dependence. Journal of Studies on Alcohol and Drugs, 57(4), 352. doi:10.1111/j.1530-0277.1996.tb01680.x

Goschke, T. (2000). Intentional reconfiguration and involuntary persistence in task set switching. In S. Monsell \& J. Driver (Eds.), Control of cognitive processes: Attention and performance XVIII (pp.331-355). Cambridge, MA. MIT Press.

Goyer, P. F., Andreason, P. J., Semple, W. E., Clayton, A. H., King, A. C., Compton-Toth, B. A., ... \& Cohen, R. M. (1994). Positron-emission tomography and personality disorders. Neuropsychopharmacology, 10(1), 21-28. doi:10.1038/npp.1994.3

Grafman, J., Schwab, K., Warden, D., Pridgen, A., Brown, H. R., \& Salazar, A. M. (1996). Frontal lobe injuries, violence, and aggression a report of the Vietnam head injury study. Neurology, 46(5), 1231-1231. doi:10.1212/wnl.46.5.1231

Greve, K. W., Love, J., Sherwin, E., Stanford, M. S., Mathias, C., \& Houston, R. (2002). Cognitive strategy usage in long-term survivors of severe traumatic brain injury with persisting impulsive aggression. Personality and Individual Differences, 32, 639-647. doi:10.1016/s0191-8869(01)00066-6

Gyurak, A., Goodkind, M. S., Madan, A., Kramer, J. H., Miller, B. L., \& Levenson, R. W. (2009). Do tests of executive functioning predict ability to downregulate emotions spontaneously and when instructed to suppress?. Cognitive, Affective, \& Behavioral Neuroscience, 9(2), 144-152. doi:10.3758/cabn.9.2.144

Hartup, W. W. (1974). Aggression in childhood: Developmental perspectives. American Psychologist, 29(5), 336. doi: 10.1037/h0037622

Heatherton, T. F., \& Wagner, D. D. (2011). Cognitive neuroscience of self-regulation failure. 
Trends in Cognitive Sciences, 15(3), 132-139. doi: 10.1016/j.tics.2010.12.005

Hecht, L.K., Berg, J.M., Lilienfeld, S.O., Latzman, R.D. (in press). Parsing the heterogeneity between psychopathy and aggression: differential associations across age and gender. Personality Disorders: Theory, Research, and Treatment.

Hecht, L. K., \& Latzman, R. D. (2015). Revealing the nuanced associations between facets of trait impulsivity and reactive and proactive aggression. Personality and Individual Differences, 83, 192-197.

Herd, S. A., Hazy, T. E., Chatham, C. H., Brant, A. M., \& Friedman, N. P. (2014). A neural network model of individual differences in task switching abilities. Neuropsychologia, $62,375-389$.

Herrenkohl, T. I., Maguin, E., Hill, K. G., Hawkins, J. D., Abbott, R. D., \& Catalano, R. F. (2000). Developmental risk factors for youth violence. Journal of Adolescent Health, 26(3), 176-186. doi:10.1016/s1054-139x(99)00065-8

Homack, S., Lee, D., \& Riccio, C. A. (2005). Test Review: Delis-Kaplan Executive Function System. Journal of Clinical and Experimental Neuropsychology, 27(5), 599-609. doi:10.1080/13803390490918444

Hubbard, J. A., Dodge, K. A., Cillessen, A. H. N., Coie, J. D., \& Schwartz, D. (2001). The dyadic nature of social information processing in boys' reactive and proactive aggression. Journal of Personality and Social Psychology, 80, 268-280. doi: 10.1037/00223514.80.2.268

Hubbard, J. A., Smithmyer, C. M., Ramsden, S. R., Parker, E. H., Flanafan, K. D., Dearing, K. F., Relyea, N., \& Simons, R. F. (2002). Observational, physiological, and self-report 
measures of children's anger: Relations to reactive versus proactive aggression. Child Development, 73, 1101-1118. doi: 10.1111/1467-8624.00460

Hughes, C., Dunn, J., \& White, A. (1998). Trick or treat? Uneven understanding of mind and emotion and executive dysfunction in "hard-to-manage" preschoolers. Journal of Child Psychology and Psychiatry, 39(7), 981-994. doi:10.1111/1469-7610.00401

Hughes, C., White, A., Sharpen, J., \& Dunn, J. (2000). Antisocial, angry, and unsympathetic: "hard-to-manage" preschoolers' peer problems and possible cognitive influences. Journal Of Child Psychology And Psychiatry, And Allied Disciplines, 41(2), 169-179. doi: $10.1111 / 1469-7610.00558$

Hyde, J. S. (1984). How large are gender differences in aggression? A developmental metaanalysis. Developmental Psychology, 20(4), 722. doi: 10.1037/0012-1649.20.4.722

Jurado, M. B., \& Rosselli, M. (2007). The elusive nature of executive functions: a review of our current understanding. Neuropsychology Review, 17(3), 213-233. doi: 10.1007/s11065007-9040-z

Jones, L. B., Rothbart, M. K., \& Posner, M. I. (2003). Development of executive attention in preschool children. Developmental Science, 6(5), 498-504.

Kline, R.B. (2005). Principles and practice of structural equation modeling (2nd ed.). New York: Guilford Press.

Latzman, R. D., \& Markon, K. E. (2010). The factor structure and age-related factorial invariance of the Delis-Kaplan Executive Function System (D-KEFS). Assessment, 17(2), 172-184. doi:10.1177/1073191109356254

Latzman, R. D., \& Vaidya, J. G. (2013). Common and distinct associations between aggression and alcohol problems with trait disinhibition. Journal of Psychopathology and 
Behavioral Assessment, 35(2), 186-196. doi:10.1007/s10862-012-9330-5

Latzman, R. D., Elkovitch, N., Young, J., \& Clark, L. (2010). The contribution of executive functioning to academic achievement among male adolescents. Journal of Clinical and Experimental Neuropsychology, 32(5), 455-462. doi:10.1080/13803390903164363

Latzman, R. D., Vaidya, J. G., Clark, L. A., \& Watson, D. (2011). Components of disinhibition (vs. constraint) differentially predict aggression and alcohol use. European Journal of Personality, 25(6), 477-486. doi:10.1002/per.821

Lehto, J. E., Juujärvi, P., Kooistra, L., \& Pulkkinen, L. (2003). Dimensions of executive functioning: Evidence from children. British Journal of Developmental Psychology, 21(1), 59-80. doi:10.1348/026151003321164627

Little, T. D., Cunningham, W. A., Shahar, G., \& Widaman, K. F. (2002). To parcel or not to parcel: Exploring the question, weighing the merits. Structural equation modeling, 9(2), 151-173. doi: 10.1207/S15328007SEM0902_1

Loeber, R. 1982. The stability of antisocial and delinquent child behavior: a review. Child Development, 53(6), 1431-1446. doi:10.2307/1130070

Loeber, R., \& Hay, D. (1997). Key issues in the development of aggression and violence from childhood to early adulthood. Annual Review of Psychology, 48(1), 371-410. doi:10.1146/annurev.psych.48.1.371

MacDonald, K.B. (2008). Effortful control, explicit processing, and the regulation of human evolved predisposition. Psychology Review, 115, 1012-1031. doi:10.1037/a0013327

McAuliffe, M. D., Hubbard, J. A., Rubin, R. M., Morrow, M. T., \& Dearing, K. F. (2006). Reactive and proactive aggression: Stability of constructs and relations to correlates. The Journal of Genetic Psychology, 167, 365-382. doi:10.3200/gntp.167.4.365-382 
McCabe, D. P., Roediger III, H. L., McDaniel, M. A., Balota, D. A., \& Hambrick, D. Z. (2010). The relationship between working memory capacity and executive functioning: evidence for a common executive attention construct. Neuropsychology, 24(2), 222. doi: $10.1037 / \mathrm{a} 0017619$

Miller, E. K., \& Cohen, J. D. (2001). An integrative theory of prefrontal cortex function. Annual Review Of Neuroscience, 24167-202. doi:10.1146/annurev.neuro.24.1.167

Miller, J. D., \& Lynam, D. R. (2006). Reactive and proactive aggression: Similarities and differences. Personality and Individual Differences, 41(8), 1469-1480. doi: 10.1016/j.paid.2006.06.004

Miyake, A., \& Friedman, N. P. (2012). The nature and organization of individual differences in executive functions four general conclusions. Current Directions in Psychological Science, 21(1), 8-14. doi: 10.1177/0963721411429458

Miyake, A., Friedman, N. P., Emerson, M. J., Witzki, A. H., Howerter, A., \& Wager, T. D. (2000). The unity and diversity of executive functions and their contributions to complex “frontal lobe" tasks: A latent variable analysis. Cognitive Psychology, 41(1), 49-100. doi:10.1006/cogp.1999.0734

Miyake, A., Friedman, N. P., Rettinger, D. A., Shah, P., \& Hegarty, M. (2001). How are visuospatial working memory, executive functioning, and spatial abilities related? A latent-variable analysis. Journal of Experimental Psychology: General, 130(4), 621.

Moffitt, T. E. (1993). Adolescence-limited and life-course-persistent antisocial behavior: a developmental taxonomy. Psychological Review, 100(4), 674. doi:10.1037/0033$295 \times .100 .4 .674$

Morgan, A. B., \& Lilienfeld, S. O. (2000). A meta-analytic review of the relation between 
antisocial behavior and neuropsychological measures of executive function. Clinical Psychology Review, 20(1), 113-136. doi:10.1016/s0272-7358(98)00096-8

Munakata, Y., Herd, S. A., Chatham, C. H., Depue, B. E., Banich, M. T., \& O’Reilly, R. C. (2011). A unified framework for inhibitory control. Trends in cognitive sciences, 15(10), 453-459.

Nigg, J. T. (2000). On inhibition/disinhibition in developmental psychopathology: Views from cognitive and personality psychology and a working inhibition taxonomy. Psychological Bulletin, 126, 220-246. doi:10.1037//0033-2909.126.2.220

Ochsner, K. N., \& Gross, J. J. (2008). Cognitive emotion regulation insights from social cognitive and affective neuroscience. Current Directions in Psychological Science, 17(2), 153-158. doi: 10.1111/j.1467-8721.2008.00566.x

Ogilvie, J. M., Stewart, A. L., Chan, R. C., \& Shum, D. H. (2011). Neuropsychological measures of executive function and antisocial behavior: a meta-analysis. Criminology, 49(4), 1063. doi:10.1111/j.1745-9125.2011.00252.x

Parrott, D. J., \& Giancola, P. R. (2007). Addressing "The criterion problem" in the assessment of aggressive behavior: Development of a new taxonomic system. Aggression and Violent Behavior, 12(3), 280-299. doi:10.1016/j.avb.2006.08.002

Patrick, M. E., Blair, C., \& Maggs, J. L. (2008). Executive function, approach sensitivity, and emotional decision making as influences on risk behaviors in young adults. Journal of Clinical and Experimental Neuropsychology, 30(4), 449-462. doi:10.1080/13803390701523109

Pihl, R. O., Assaad, J. M., \& Hoaken, P. N. S. (2003). The alcohol-aggression relationship and differential sensitivity to alcohol. Aggressive Behavior, 29(4), 302-315. 
doi: $10.1002 / a b .10072$

Posner, M. I., \& Rothbart, M. K. (2000). Developing mechanisms of self-regulation. Development and Psychopathology, 12, 427-441. doi:10.1017/s0954579400003096

Poulin, F., \& Boivin, M. (2000). Reactive and proactive aggression: Evidence of a two-factor model. Psychological Assessment, 12(2), 115-122. doi:10.1037/1040-3590.12.2.115

Raaijmakers, M. A., Smidts, D. P., Sergeant, J. A., Maassen, G. H., Posthumus, J. A., Van Engeland, H., \& Matthys, W. (2008). Executive functions in preschool children with aggressive behavior: Impairments in inhibitory control. Journal of Abnormal Child Psychology, 36(7), 1097-1107. doi:10.1007/s10802-008-9235-7

Raine, A., Dodge, K., Loeber, R., Gatzke-Kopp, L., Lynam, D., Reynolds, C., ... \& Liu, J. (2006). The Reactive-Proactive Aggression Questionnaire: Differential correlates of reactive and proactive aggression in adolescent boys. Aggressive Behavior, 32(2), 159171. doi:10.1002/ab.20115

Raine, A., Meloy, J. R., Bihrle, S., Stoddard, J., LaCasse, L., \& Buchsbaum, M. S. (1998). Reduced prefrontal and increased subcortical brain functioning assessed using positron emission tomography in predatory and affective murderers. Behavioral Sciences \& the Law, 16(3), 319-332. doi: 10.1002/(SICI)1099-0798(199822)16:3

Razza, R. A., \& Blair, C. (2009). Associations among false-belief understanding, executive function, and social competence: A longitudinal analysis. Journal of Applied Developmental Psychology, 30(3), 332-343. doi:10.1016/j.appdev.2008.12.020

Reidy, D. E., Foster, J. D., \& Zeichner, A. (2010). Narcissism and unprovoked aggression. Aggressive Behavior, 36(6), 414-422. doi:10.1002/ab.20356

Riggs, N. R., Jahromi, L. B., Razza, R. P., Dillworth-Bart, J. E., \& Mueller, U. (2006). Executive 
function and the promotion of social-emotional competence. Journal of Applied Developmental Psychology, 27(4), 300-309. doi:10.1016/j.appdev.2006.04.002

Robinson, H., Calamia, M., Gläscher, J., Bruss, J., \& Tranel, D. (2013). Neuroanatomical correlates of executive functions: A neuropsychological approach using the EXAMINER battery. Journal of the International Neuropsychological Society, 19(3), 000-000. doi:10.1017/s135561771300060x

Rothbart, M. K., Derryberry, D., \& Posner, M. I. (1994). A psychobiological approach to the development of temperament. In J. E. Bates, T. D. Wachs (Eds.), Temperament: Individual Differences at the Interface of Biology and Behavior, (pp. 83-116). Washington, DC, US: American Psychological Assocaition. doi:10.1037/10149-003

Rothbart, M. K., Ellis, L. K., Rosario Rueda, M., \& Posner, M. I. (2003). Developing mechanisms of temperamental effortful control. Journal of Personality, 71(6), 11131144. doi: $10.1111 / 1467-6494.7106009$

Rose, S. A., Feldman, J. F., \& Jankowski, J. J. (2011). Modeling a cascade of effects: the role of speed and executive functioning in preterm/full-term differences in academic achievement. Developmental science, 14(5), 1161-1175. doi: 10.1111/j.14677687.2011.01068.x

Rueda, M. R., Posner, M. I., \& Rothbart, M. K. (2005). The development of executive attention: Contributions to the emergence of self-regulation. Developmental Neuropsychology, 28(2), 573-594. doi: 10.1207/s15326942dn2802_2

Rueda, M., Posner, M. I., \& Rothbart, M. K. (2011). Attentional control and self- regulation. In K. D. Vohs, \& R. F. Baumeister (Eds.), Handbook of Self-Regulation: Research, Theory, and Applications (2nd ed.) (pp. 284-299). New York, NY US: Guilford Press. 
Séguin, J. R. (2009). The frontal lobe and aggression. European Journal of Developmental Psychology, 6(1), 100-119. doi:10.1080/17405620701669871

Séguin, J. R., Arseneault, L., Boulerice, B., Harden, P. W., \& Tremblay, R. E. (2002). Response perseveration in adolescent boys with stable and unstable histories of physical aggression: The role of underlying processes. Journal of Child Psychology and Psychiatry, 43(4), 481-494. doi:10.1111/1469-7610.00039

Séguin, J. R., Pihl, R. O., Harden, P. W., Tremblay, R. E., \& Boulerice, B. (1995). Cognitive and neuropsychological characteristics of physically aggressive boys. Journal of Abnormal Psychology, 104(4), 614-624. doi:10.1037/0021-843x.104.4.614

Séguin, J., \& Zelazo, P. (2005). Executive Function in Early Physical Aggression. In R. E. Tremblay, W. W. Hartup, J. Archer (Eds.), Developmental Origins of Aggression (pp. 307-329). New York, NY, US: Guilford Press.

Siever, L. J. (2008). Neurobiology of aggression and violence. The American Journal Of Psychiatry, 165(4), 429-442. doi:10.1176/appi.ajp.2008.07111774

Stanford, M. S., Greve, K. W., \& Gerstle, J. E. (1997). Neuropsychological correlates of selfreported impulsive aggression in a college sample. Personality and Individual Differences, 23(6), 961-965. doi:10.1016/s0191-8869(97)00120-7

Sylvester, C. Y. C., Wager, T. D., Lacey, S. C., Hernandez, L., Nichols, T. E., Smith, E. E., \& Jonides, J. (2003). Switching attention and resolving interference: fMRI measures of executive functions. Neuropsychologia, 41(3), 357-370.

Tabibnia, G., Monterosso, J. R., Baicy, K., Aron, A. R., Poldrack, S., Chakrapani, S., Lee, B., \& London, E. D. (2011). Different forms of self-control share a neurocognitive substrate. The Journal of Neuroscience, 31, 4805-4810 
Tranel, D. (1994). "Acquired sociopathy": the development of sociopathic behavior following focal brain damage. Progress in Experimental Personality \& Psychopathology Research, 285.

Tremblay, R. E. (2000). The development of aggressive behaviour during childhood: What have we learned in the past century? International Journal of Behavioral Development, 24(2), 129-141. doi:10.1080/016502500383232

Vaughan, L., \& Giovanello, K. (2010). Executive function in daily life: Age-related influences of executive processes on instrumental activities of daily living. Psychology and aging, 25(2), 343. Doi: 10.1037/a0017729

Villemarette-Pittman, N. R., Stanford, M. S., \& Greve, K. W. (2003). Language and executive function in self-reported impulsive aggression. Personality and Individual Differences, 34(8), 1533-1544. doi:10.1016/s0191-8869(02)00136-8

Vitaro, F., Brendgen, M., \& Barker, E. D. (2006). Subtypes of aggressive behaviors: A developmental perspective. International Journal Of Behavioral Development, 30(1), 1219. doi:10.1177/0165025406059968

Vitaro, F., Brendgen, M., \& Tremblay, R. E. (2002). Reactively and proactively aggressive children: Antecedent and subsequent characteristics. Journal of Child Psychology and Psychiatry and Allied Disciplines, 43, 495-506. doi:10.1111/1469-7610.00040

Walters, G. D. (2007). Measuring proactive and reactive criminal thinking with the PICT. Journal of Interpersonal Violence, 22, 371-385. doi:10.1177/0886260506296988 Washburn, D.A., Latzman, R.D., Schwartz, N.B., Bramlett, J. (2015). Attention as a cause and effect of perception (pp. 126-147). In J.L. Szalma, M. Scerbo, R. Parasuraman, P.A. 
Hancock, \& R. Hoffman (Eds.), Cambridge Handbook of Applied Perception Research. New York: Cambridge University Press. 